\section{THE ROYAL PHOTOGRAPHIC SOCIETY'S ANNUAL EXHIBITION.}

THIS exhibition, which will remain open for a few weeks, is, as usual, at the New Gallery, Regent Street. It is divided into several sections, namely :(I) pictorial; (2) scientific and technical; (3) lantern-slides; (4) autochromes; (5) portraits of eminent British subjects from the society's collection; (6) general professional work; (7) trade exhibits of apparatus and materials. We notice a welcome though slight tendency in the pictorial section to return to the old custom of stating by what process the print has been produced, information that is not only due to any prospective purchaser, but also gives the exhibit an interest for the technical student, while it in no sense detracts from its pictorial value.

There are no new methods of photography in colours. The coloured prints in the pictorial section are, so far as we notice, coloured by hand. The chief interest of the autochromes lies in the application of these plates to the photography of other subjects than portraits, views, and still-life groups. Dr. H. G. D. Brockman demonstrates, in a series of thirteen, their usefulness in recording the presence of blood-stains in a room, on various articles of clothing, and on a bottle, in connection with a trial for murder. In some cases the article was "subjected to a stream of oxygen in an atmosphere which was supersaturated with water vapour and at a temperature of $70^{\circ} \mathrm{F}$. As a consequence, certain tarry-looking stains on the boots which were thought to be blood became ruddy." The effect of this treatment is shown by comparative photographs. The same exhibitor has eight autochromes of pathological subjects, which will convey a very good idea of what may be expected when these plates are used for such work. Mr. C. P. Butler shows a direct photograph of the solar spectrum taken on "Uto" paper, in which the colours of the spectrum are excellently rendered.

The natural history division includes a few autochromes which show the great advantage of colour photographs of such subjects, in spite of the fact that the tints depend to a certain extent upon the manipulation of the plates. In a very considerable collection of monochrome photographs, "The Stoat," by Mr. Douglas English, appears, we believe, for the first time. There are several series of pictures of great interest. Mr. William Farren, for example, gives fourteen photographs of the nest of a song thrush, which illustrate the rapid growth of the young birds and the feeding of them by the parents, and he appends a short history of the events, with dates and many details, from the hatching to the time the nestlings left the nest. Similar series are contributed by Mr. Alfred Taylor, which illustrate the "domestic habits of the song thrush" and "the life-history of the tawny owl." A series of eight radiographs, by Messrs. Wilson and Blackall, show the gradual development of the bones of the hand from three to eighteen years of age. Among the photomicrographs, some examples of low-power work, of five and ten diameters, by Mr. W. F. Cooper, are specially noteworthy.

The progress made in cutting the Panama Canal is clearly shown in ten photographs by Dr. Vaughan Cornish, with a map and vertical section. Mr. J. Howden Wilkie has succeeded in two cases in photographing the same flash of lightning with both a stationary and a moving camera. Captain Owen Wheeler; who has made a speciality of telephotography, demonstrates in a remarkable way that it is possible to produce telephotographs of seven and nine diameters' magnification of such good definition that they will well stand a further enlargement of four diameters. The detection of forgery by photographic means is well illustrated by. Dr. R. A. Reiss.

Astronomical work is not largely represented, the only exhibits we noticed being the spectrum of "Mars" in the region of "a" compared with spectra of the moon, by Mr. V. M. Slipher, which shows the presence of water vapour in the atmosphere of the planet, and some lanternslides of the sun and sun-spots made by Mr. C. W. Barlow using an old $4 \frac{1}{4}$-inch refractor, with a deep yellow screen interposed.

No. 2030 , VOL. 78$]$

\section{THE BRITISH ASSOCIATION.}

\section{SECTION G.}

ENGINEERING.

Opening Address by Dugald Clerk, F.R.S., M.Inst.C.E., F.C.S., President of the Section.

At the middle of the last century the steam engine had attained to a high degree of perfection. Its development was, it is true, incomplete, but it had been successfully applied to all the great duties of the mine, the waterworks, the factory, the railway, and the steamship. The engines were mechanically excellent; the fuel economy was good, and they were built in units of thousands of horse-power. Steam power, in fact, was revolutionising the whole of the social and industrial conditions of the globe. Notwithstanding this great material and engineering success, the world was in complete darkness as to the connection between steam motive-power and heat. It was seen that motive-power of almost any magnitude could be obtained by the agency of heat; but how it was obtained and how much power was connected with a given quantity of heat was quite unknown. The fuel consumptions of existing engines were known, and certain modes of improving economy were evident, and engineers were busily engaged in testing these modes by the slow but sure methods of invention, design, construction, and operation in practical work; but in this they had but little aid from pure science.

The science of thermodynamics did not yet exist.

New light was dawning, however, which gradually illumined the whole world of pure science and engineering practice.

Men of the first rank in intellect-Newton, Cavendish Rumford, Young, and Davy-had long before expressed the opinion that heat was not material in its nature, but was a mode of motion; but their opinions, although to some extent supported by experiment, made little impression upon the scientific world, and in $185^{\circ}$ we still find the most distinguished physicists adhering to the " caloric" or material theory of heat.

The great change, from the errors of the old theories to the truth of the new, was due to the work of Joule, Thomson, and Rankine in Great Britain, and of Carnot, Meyer, Clausius, Helmholtz, and Hirn on the Continent. The story begins with the work of Carnot in 1824 , who published in Paris in that year a pamphlet entitled "Reflections upon the Motive Power of Heat." $\mathrm{He}$ was attracted by the problem of the steam engine and the air engine. He saw that heat and motive power were connected in some manner, and he endeavoured to settle in a quantitative way the limits of that connection by the invention of an ideal series of operations by means of which the greatest conceivable amount of mechanical power may be obtained from a given quantity of heat in given circumstances. For the purpose of his demonstration he assumes only two things: (I) That if heat be added to any body under standard conditions of temperature, pressure, and volume, and the body be carried through any series of mechanical processes, returning ultimately to the standard condition of temperature, pressure, and volume, then the quantity of heat added to the body is the same as that which has been discharged from it; (2) no process can exist whereby a given mechanical energy can increase its own quantity. On these indisputable assumptions he bases his ideal cycle, which consists of four simple and easily imagined operations, occurring within a cylinder behind a piston, so arranged that during the cycle work can be done by the working fluid upon the piston or work done by the piston on the working fluid.

First Operation.-The given volume of the working fluid is to be imagined as confined at its highest temperature and pressure behind the piston, and heat is to be added to keep the temperature constant, while the fluid expands, moving the piston and doing work upon it.

Second Operation.-The supply of heat is cut off, and the working fluid expands also during work on the piston, while its temperature falls to the lowest point and its volume increases to its maximum. 
Third Operation.-The piston returns, compressing the working fluid, but allowing the heat of compression to escape, so that the temperature remains during the operation at its lowest point.

Fourth Operation.-The piston compresses the working fluid, without allowing any loss of heat, to such an extent that the temperature rises again to its highest point, and the working fluid exists at the end of this operation at the same volume, pressure, and temperature as at the beginning.

This assumed series of operations would give a certain available work area, the indicated power of the engine, inasmuch as the work done by the working fluid would be greater than that done upon it. If, however, it be assumed that in all the operations the direction of motion of the piston be reversed, then compression without loss of heat would take place in the second operation; further compression, but with sufficient heat loss to keep temperature constant, would occur on the first operation; the fourth operation would follow with expansion, and the third operation would conclude also with expansion. The engine would be reversed by beginning with the second operation, moving the piston backwards in the order second, first, fourth, third. Carnot shows that this reverse operation would be performed by exactly the same amount of work as was given out by the direct operation, and that an amount of heat would be returned at the higher cemperature equal to that which was added in the first case.

An engine which fulfils these conditions, Carnot states, will give the greatest amount of work which can be obtained from a given quantity of heat falling through a given temperature range. And it is evident that this must be so, because, if we assume the existence of any engine under the same conditions giving a greater amount of work from the same heat, then that engine could drive a Carnot engine in the reverse direction in such proportion as to return to the higher temperature a greater amount of heat than it abstracted, and so mechanical energy could be obtained without any heat fall whatever. This marvellous demonstration is obviously independent of the nature of the working fluid; it applies equally to all working substances, whether solid, liquid, or gaseous, whether physical state changes or noi. It at once gives a standard of the limit of mechanical power which could possibly be obtained from a given amount of heat and a given temperature fall.

The Carnot cycle operations, as here given, are applicable either to the material or to the dynamical theory of heat; but Carnot originally stated that the whole of the heat added in the first operation was to be discharged in the third. Under the material or caloric theory, work was supposed to be done by the fact of fall in temperature. Naturally, as the heat was material it could not be destroyed or changed into mechanical energy. The production of mechanical energy was supposed to be incidental to the fall of temperature, much in the same way as mechanical energy was produced by the fall of waterlevel, and this analogy is used throughout Carnot's work of 1824 .

Carnot thus susceeded in proposing a standard of efficiency which was applicable to any heat engine, whatever the working fluid and whatever the operative cycle. By his method a limit could be set, fixing the maximum of mechanical energy to be obtained from a given heat quantity and a given temperature range. To reduce this to numerical values it was necessary, however, to experiment on any one working fluid within the desired temperature range in order to determine the work area in its relation to heat quantity and temperature fall. Carnot's writings show that he intended to make such observations; and, had he suoceeded, thermodynamics would have become a science at an early date. Carnot's death, however, in 1832, at the sadly early age of thirty-six years, prevented this development.

The name of Sadi Carnot will always be remembered by mankind as the founder of one branch of the thermodynamics of the heat engine.

His work remained practically without notice for thirteen years after his death, when, fortunately, it attracted the attention of William Thomson during his NO. 2030, VOL. 78] attendance at the Laboratory of Regnault in the year 1845. Thomson was then twenty-one years of age, and had already attained a considerable scientific reputation. $\mathrm{He}$ took up the study of Carnot's work with enthusiasm. He became Professor of Natural Philosophy in the University of Glasgow in 1846 , and in 1848 he read a Paper before the Cambridge Philosophical Society "On an Absolute Thermometric Scale founded on Carnot's Theory of the Motive Power of Heat and calculated from Regnault's Observations." Like Carnot, Thomson accepted the " material " or " caloric" theory of the nature of heat, although, like Carnot also, he had doubts as to its truth. Assuming its truth, however, he carried Carnot's reasoning much further, and deduced from the Carnot cycle a thermometric scale which was absolute in the sense that it defined the idea of temperature independently of the properties of any particular body.

It is very difficult to carry one's mind back to the material theory of heat, but it is necessary to do so in order to appreciate the rigid accuracy of the reasoning of both Carnot and Thomson; and it is especially desirable to do so in order to understand the great step made in this Paper. Aocording to the "caloric " theory, heat was supposed to be a subtle elastic fluid which permeated the pores of bodies and filled the interstices between the molecules of matter. The fundamental quality imagined of this caloric or heat fluid was that of indestructibility and uncreatability by any humanly controlled process. Bodies became warmer when caloric was added to them, and grew colder as it left them. Caloric, however, might be added to a body without heating it. In this case the heat was called "latent," and the state of the body changed from solid to liquid or from liquid to vapour or gas.

Caloric, too, was required in greater quantities for some substances than others in order to warm the body equally. The capacity for caloric was thus greater in some bodies than in others.

If any particular body were heated without change of state it was hotter; that is, its temperature rose when the quantity of caloric present was increased. It was not difficult to define equality of temperature. This was defined by a constant condition when brought into contact. But it was very difficult indeed to define temperature on any rational scale.

To the acute and brilliant intellect of William Thomson it became apparent that he had in the Carnot cycle a powerful instrument capable of widely general use, apart altogether from the theory of heat engines; and he here uses it in a most skilful way to give definiteness and universal application to the idea of temperature, as Prof. Larmor states, " elevating the idea of temperature from a mere featureless record or comparison of thermometers into a general principle of physical nature."

Thomson accordingly defines equal differences of temperature in terms of the reversible or Carnot engine.

Equal temperature differences are to be differences between the temperatures of the source of heat and the refrigerator, when the proportion of work produced from a given quantity of heat is the same. Thermometers graduated in degrees calculated in this way could naturally be treated as instruments based on definite principles, independently of any properties of any particular material. The idea of temperature here was in rigid logical consistency with the "caloric" theory. of heat, and it carried out completely the analogy between power derived from the same quantity of heat falling from a higher to a lower level, and resembling a fall of water in producing its effects. For equal quantities of " caloric," as of "water," temperature fall was regarded as similar to fall in space, and so an accurate idea of the nature of temperature difference is attained.

This definition, however, gave a scale greatly differing from that of mercurial, air, and other thermometers, the degrees defined by it corresponding to larger and larger intervals on the air thermometer as temperature increases. Prof. Tait pointed out also that on such a scale the temperature of a body totally deprived of heat is negativeinfinite.

All these difficulties do not detract from the fundamental importance of the idea here enunciated for the first time : the idea of an absolute thermometric scale theoretically 
applicable to all bodies-solid, liquid, and gaseous. On the "caloric" or "material" theory of heat, motive power is obtained during the letting down or fall from a higher to a lower level of a given quantity of heat. The quantity of heat does not alter in the process; it is only its relative level which alters. There is no reason, therefore, for mentally limiting the amount of mechanical energy obtainable from any given quantity of caloric, just as there is no reason for limiting the amount of mechanical energy to be mentally derived from a given weight. Any desired quantity of energy may be derived from a weight of, say, one pound, if it only be allowed to fall far enough, assuming gravity to be constant through the range.

The investigation of the work to be derived from a given quantity of heat at a given temperature is thus a matter of experiment, which can be settled by measurement of the properties of a few bodies.

Reasoning, it is conceived, in this way, Thomson follows up his absolute thermometric scale work with an investigation entitled "Carnot's Theory of the Motive Power of Heat," described in a Paper read in 1849 before the Royal Society of Edinburgh, in which he calculates from Regnault's experiments on steam the power developed by a Carnot reversible engine when using one centigrade heat unit; that is, the heat necessary to heat one pound of water through $1^{\circ} \mathrm{C}$. for temperatures from $\mathrm{I}^{\circ}$ to $23 \mathrm{I}^{\circ} \mathrm{C}$., the temperature falling in the engine in each case to $0^{\circ} \mathrm{C}$.

In this Paper he asks himself two questions: (I) What is the precise nature of the thermal agency by means of which mechanical effect is to be produced without effects of any other kind? and (2) How may the amount of the thermal agency necessary for performing a given quantity of work be estimated?

Using Regnault's values for the properties of steam, he calculates the lines of compression and expansion without heat loss, the lines of compression and expansion with heat flow at the lowest temperature, and heat addition at the highest temperature, and thus arrives at the work area per heat unit let down. He tabulates these results, and shows that what he calls Carnot's function diminishes as temperature rises, using the ordinary centigrade scale. On the caloric theory the methods are rigidly logical and correct, but some inaccuracy is introduced by the necessity of that theory for the discharge of the same amount of heat at the third operation as is taken in on the first. The Paper is of great interest, however, because it shows clearly how fully the distinguished author realises the necessity for re-examining the standard ideas of the nature of heat. Two paragraphs make this very clear:-

" 7 . Since the time when Carnot thus expressed himself the necessity of a most careful examination of the entire experimental basis of the theory of heat has become more and more urgent. Especially all those assumptions depending on the idea that heat is a substance, invariable in quantity, not convertible into any other element, and incapable of being generated by any physical agency; in fact, the acknowledged principles of latent heat would require to be tested by a most searching investigation before they ought to be admitted, as they usually have been, by almost everyone who has been engaged on the subject, whether in combining the results of experimental research or in general theoretical investigations.

" 8. The extremely important discoveries recently made by Mr. Joule, of Manchester, that heat is evolved in every part of a closed electric conductor moving in the neighbourhood of a magnet, and that heat is generated by the friction of fluids in motion, seem to overturn the opinion commonly held that heat cannot be generated, but only produced from a source where it has previously existed either in a sensible or in a latent condition. In the present state of science, however, no operation is known by which heat can be absorbed into a body without either elevating its temperature or becoming latent, and producing some alteration in its physical condition; and the fundamental axiom adopted by Carnot may be considered as still the most probable basis for an investigation of the motive power of heat, although this, and with it every other branch of the theory of heat, may ultimately require to be reconstructed upon another foundation when our experimental data are more complete. On this understanding, and to avoid a repetition of doubts, I shall refer to
Carnot's fundamental principle, in all that follows, as if its truth were thoroughly established."

In these two paragraphs Thomson sums up the whole situation in 1849 , and promises further investigation and further attempts to deduce the nature of the connection between heat and work.

Assume, then, the truth of the caloric theory of heat, as Thomson does in the 1849 Paper: We have a complete theory of the heat engine, based on the Carnot cycle, accounting for efficiencies which vary with temperature differences, but requiring no definite mechanical equivalent of heat; nay, antagonistic to the existence of such an equivalent. The caloric theory, as has been pointed out, is quite consistent with the theoretical possibility of obtaining an indefinitely great amount of mechanical energy from any given quantity of heat, provided the letting down or fall of level be indefinitely great.

At the time we are discussing- 1850 -the bare conception of the idea of an absolute zero of temperature is one which is startling in its boldness; and it must have been difficult indeed then to imagine any definite line of proof which could be followed to establish the real existence of such a physical limit. We are so familiar with the existence of very high temperatures, vastly transcending the temperatures in which we personally exist, that we can hardly conceive a temperature limit on the ascending side; that is, we can hardly think of any given high temperature which could not in quite conceivable circumstances be exceeded. We know, for example, that any metal-say platinum-may be melted if its temperature be sufficiently increased; that a further sufficient increase will convert the liquid metal to the gaseous state, and that the gaseous metal may be heated indefinitely while in that state. We know the behaviour and properties of many substances at high temperatures, and are aware of the strong tendency of all chemical compounds, when highly heated, to split up into the elementary bodies composing them. All this we appreciate, but we find it difficult to see how a point of temperature could be reached when it could be said: This is a physical limiting point on the ascending scale; we may heat a substance up to this temperature, but it is impossible to conceive of any higher temperature. It is necessary here to distinguish between a conceivable limit to an ascending temperature and a practical limit under existing conditions. We may thus place limits, say, to the temperature of coal-gas and air explosions, or the temperatures possible from the electric arc; the limit with coal gas and air depending on one set of conditions, and the electric arc upon another set, such as the vapourising point of carbon, and so on. In the same way, at the middle of last century it would have been considered quite reasonable to suppose that human existence was carried on at an intermediate plane of temperature, and that temperatures might exist as low, relatively to our mean temperature, as our known furnace and combustion temperatures are high. At this time, no doubt, such an idea was quite a reasonable one.

No such limit could be proved, even by the aid of the Carnot cycle, reasoning on the material theory of heat. If we assume that heat is material, and that in some way temperature fall doing work resembles, as Carnot supposed, the fall of water doing work in passing from a higher to a lower level, then no absolute zero is possible, because the same quantity of heat is supposed to exist at the low as at the high temperature. On this theory nothing in the idea of temperature suggests a possible physical limit. On the material theory, the notion of temperature is one to which it is exceedingly difficult to attach a precise meaning.

Thomson's promises of further investigation were fulfilled in $185^{\circ}$, in which year he definitely accepted the dynamical theory of heat and finally abandoned the material. His conclusions are given in a Memoir of the first importance which was read before the Royal Society of Edinburgh in $185 \mathrm{I}$. It was entitled " On the Dynamical Theory of Heat." Before dealing with it, however, it is desirable to consider the work of Joule and others on another side of thermodynamics.

Long before $x 5^{\circ}$ the equivalence of mechanical work and heat quantity had been accepted by many scientific men, and Rumford had, indeed, made measurements of a

No. 2030, VoL. 78] 
rough kind. It remained, however, for Joule experimentally to determine the mechanical equivalent in the most accurate manner and place what is now known as the first law of thermodynamics upon the sure basis of absolute experimental determination. His first Paper was read before the Cork Meeting of the British Association in 1843 , and at the Oxford Meeting in 1847 he read another -." On the Mechanical Equivalent of Heat"'-describing the results of experiments with paddles rotating in liquids driven by falling weights. By these years of work he had absolutely demonstrated the equivalence of heat quantity and mechanical work, so that no loophole of escape seemed possible; it appeared as if the material theory was rendered intellectually impossible to the trained intellect. This was not the fact, however, as is evident from both Joule's and Thomson's accounts of that British Association Meeting.

Foule's earlier Paper had been coolly received. Indeed, it is evident that the idea of a mechanical equivalent of heat was still distasteful to the physicists of the day, and its discussion was looked upon with dislike. Joule, at the I847 Meeting, addressed a small audience, and the account of his experiments was received without enthusiasm. This adverse atmosphere, so discouraging to the investigator, was quickly removed, however, when a young man rose to make his remarks, and, by his enthusiastic comment and clear reasoning, at once succeeded in attracting the interest of those present. This young man was William Thomson, Professor of Natural Philosophy in the University of Glasgow. Speaking of this, his first meeting with Joule, at Manchester forty-six years later, Lord Kelvin said: "I can never forget the British Association at Oxford in the year 1847 , when in one of the Sections I heard a Paper read by a very unassuming young man, who betrayed no consciousness in his manner that he had a great idea to unfold. I was tremendously struck with the Paper. I had first thought it could not be true because it was different from Carnot's theory, and immediately after the reading of the Paper.I had a few words of conversation with the author, James Joule, which was the beginning of our forty years' acquaintance and friendship.... I gained ideas which had never entered my mind before, and I thought I, too, suggested something worthy of Joule's consideration when I told him of Carnot's theory." This Meeting was indeed fateful for the future of the science of thermodynamics, as it resulted in cooperation between two men of giant intellect, who between them performed most of the experimental work which was necessary to make thermodynamics an exact science. Their work alone sufficed to place the first and second laws of thermodynamics on the firm footing of accurate experiment and logical deduction.

Although Thomson was much struck by Joule's experiments, he did not accept the dynamical theory of heat at once. As he stated himself: "I had first thought that it could not be true because it was different from Carnot's theory."

Joule's discoveries at this date may be thus expressed :-

Heat and mechanical energy are mutually convertible, and heat requires for its production, and produces by its disappearance, mechanical energy in the proportion of 1390 foot-pounds for each centigrade heat unit, a heat unit being the amount of heat necessary to heat one pound of water through $\mathrm{i}^{\circ} \mathrm{C}$.

Knowing, as Thomson did, that mechanical energy could be produced by the agency of heat, but that its amount varied with the temperature and temperature fall, Joule's discoveries seemed antagonistic to Carnot's demonstration; and, convinced as he was that Carnot's law was true, he naturally felt at first that there must be some other way of looking at Joule's results than that adopted by Joule himself.

Joule naturally believed in his own manner of looking at his results, and he apparently agreed with Thomson as to the antagonism between what may be here called the Carnot and Joule laws.

The material theory of heat might have been true; in which case there was no more need for any direct quantitative connection between heat quantity and mechanical energy than between the mass of a body and its mechanical energy. Any unit of mass may acquire any conceivable amount of mechanical energy if its velocity be great enough, and so any unit of heat on the caloric theory may produce any conceivable amount of mechanical energy if the temperature fall be great enough. Joule considered the Carnot law to be so inconsistent with his law that in one of his Papers he proposes its abandonment as inconsistent with discovered facts. At this point the two ideas seem to be in opposition. The germ of reconciliation, however, is found in observations by Thomson in both the 1848 and 1849 Papers. In paragraph 8 , quoted here from the latter Paper, it is stated :-

"In the present state of science, however, no operation is known by which heat can be absorbed into a body without either elevating its temperature or becoming latent and producing some alteration in its physical condition.'

This is equivalent to saying that no case has been observed where heat disappears doing mechanical work. In a note occurring in the same Paper he alludes to the fact that engineers always assume that the amount of heat found in the condenser of the steam engine was the same as that taken into the engine by the steam, in the following terms:-

"So generaily. is Carnot's principle tacitly admitted as an axiom that its application in this case has never, so far as I am aware, been questioned by practical engineers."

This was quite accurate. Hirn's demonstration that heat disappears in a steam engine when work is done was not made until 1857 , eight years later.

In the 1848 Paper he states:-

"The experiments of Mr. Joule of Manchester seem to indicate an actual conversion of mechanical effect into caloric. No experiment, however, is adduced in which the converse operation is exhibited; but it must be confessed that as yet much is involved in mystery with reference to these fundamental questions of natural philosophy."

Here we find Thomson's mind engaged-in 1848 and 1849-with the very matter requiring proof. Joule had proved the generation of heat by means of mechanical work: Thomson required the proof of the converse casethe disappearance of heat when mechanical work was done by the working fluid.

This proof was forthcoming in the results of experiments on the compression and expansion of air. Accordingly, we find the Carnot and Joule principles reconciled in Thomson's Paper of $185 \mathrm{I}$, and the important deduction made of an absolute zero of temperature at $-273^{\circ}$ on the centigrade scale. The introduction of the idea of the mechanical equivalent of heat leads at once to an absolute zero of temperature, and allows of the determination of this physical lower limit by the use of the Carnot cycle for investigating the efficiency of a perfect engine using any working fluid. Air was the working fluid actually investigated, and the determination of its properties at ordinary temperatures was a vitally important result of the cooperation of Thomson and Joule. Their experiments lasted for many years, and their rigorous investigation disclosed the fact that internal work was done in expanding a gas; in fact, that in a gas expanding isothermally doing work, part of the heat only disappeared in external work and part was absorbed in separating the molecules.

The Joule and Carnot laws are now known as the first and second laws of thermodynamics.

The second law, in modern form, may be thus stated :-

Although heat and work are mutually convertible and in definite and invariable proportions, yet no conceivable heat engine is able to convert all the heat given to it into work. Apart altogether from practical limitations, a certain portion of the heat must be passed from the hot body to the cold body in order that the remainder may assume the form of mechanical energy.

The proportion of the total heat convertible into mechanical energy depends on the absolute temperatures of the hot and cold bodies; it is unity minus the lower absolute temperature upon the upper absolute temperature.

It appears that during Thomson's struggle to reconcile the two apparently opposing laws, Clausius, who had seen the same difficulty, arrived independently at its solution and published a.Paper, "On the Motive Power of Heat and the Laws of Heat which may be deduced therefrom," at the Berlin Academy in . February, 1850. In this Paper, Clausius discusses Thomson's difficulties, and No. 2030, vOL. 78$]$ 
also arrives at the conclusion that the Carnot cycle may be reconciled to Joule's law by the omission of the supposition that during the third process the same amount of heat is discharged from the cool body as was taken in from the hot one. He states :-

"On a nearer view of the case we find that the new theories were opposed not to the real fundamental principle of Carnot, but to the addition that no heat is lost. For it is quite possible that in the production of work both may take place at the same time: a certain portion of heat may be consumed and a further portion transmitted from a warm body to a cold one; and both portions may stand in a certain definite relation to the quantity of work produced. This will be made plainer as we proceed; and it will be moreover shown that the inference to be drawn from both assumptions may not only exist together, but that they may mutually support each other."

In his $185 x$ Paper, Thomson gives Clausius full credit for solving the difficulty between the Carnot and the Joule principles. Thomson gives Clausius the full credit for priority, but states that he was working on the same problem and had arrived at the same solution in the year I $85^{\circ}$, before he had seen Clausius' work. Clausius, however, assumed the theory of a permanent gas, which required the absence of internal work, but Thomson was not prepared to assume this without experiment. This determination rigidly to prove every necessary assumption, and his clear conception of the points necessary for proof, led to the extensive series of researches undertaken by Thomson and Joule with the object of determining how much gas thermometers differ from an absolute scale as determined by the combination of the Joule and Carnot laws.

Rankine, as early as 1849 , arrived at the general equation of thermodynamics which expresses the relation between heat and mechanical energy, and indicated the result of his investigations to the Royal Society of Edinburgh in February, 1850 . Rankine thus arrived independently at the same result as Clausius about the same time. Both Rankine and Clausius, however, adopted certain theories as to the molecular structures and motions of gases, and their demonstrations to some extent depended upon their theories. To Thomson and Joule we are deeply indebted for the rigid proof of the two laws and for the rigid deduction of the modern scale of temperature and the determination of absolute zero in its modern form. Thomson now thus defines temperature :-

"The temperatures of two bodies are proportional to the quantities of heat respectively taken in and given out in localities at one temperature and at the other respectively, by a material system subjected to a complete cycle of perfectly reversible thermodynamic operations, and not allowed to part with or take in heat at any other temperature; or, the absolute values of two temperatures are to one another in the proportion of the heat taken in to the heat rejected in a perfect thermodynamic engine, working with a source and refrigerator at the higher and lower of the temperatures respectively."

This definition leads to an absolute scale of temperature which is independent of the substance operated on, and Joule and Thomson's experiments have shown that this scale differs but slightly from that of the ordinary air thermometer. Joule had suggested to Thomson, in a letter to him in $I 848$, that the probable value of Carnot's function is the reciprocal of the absolute temperature as measured on a perfect gas thermometer.

Thus Clausius appears to have anticipated Thomson, not in the suggestion of an absolute scale of temperature, but in the idea of an absolute zero founded upon the combination of Carnot's law and Joule's law. Thomson, in his. Papers, very modestly attributes the second lawthe law of the transformation of heat-to Carnot and Clausius; but in this he undervalued his work, because Clausius appears to have assumed what Thomson and Joule proved; that is, the coincidence of the absolute scale with the air thermometer scale.

It will thus be seen that the position usually assumed by the engineer at 1850 , of the equality between heat given to the engine and heat given to the condenser, was fundamentally untrue. Without this deduction, however, no determination of values of the Carnot function could have led to the determination of an absolute zero. According to the material theory, as seen in the light of Carnot's cycle, a heat unit could give an indefinitely increased amount of work with lowering of the temperature. Nothing in the theory sets a limit to this increase, and, accordingly, there is nothing to suggest an absolute zero. Immediately, however, we accept the dynamical theory of heat we find that a pound of water requires the exertion of 1390 foot-pounds of work to heat it through $\mathrm{I}^{\circ} \mathrm{C}$. We also know from the Carnot cycle that under ordinary conditions of human existence only a portion of this work can be returned; but as no conditions could conceivably exist in which a greater amount of work could be obtained from a pound of water than the 1390 foot-pounds put into it to heat it through $I^{\circ} \mathrm{C}$., it follows that, inasmuch as the Carnot function increases with diminishing temperature, the limit of temperature is reached when, according to the Carnot cycle, the whole of that work, put into the pound of water, can be got out again as work. This limit is the absolute zero of temperature. No lower temperature is conceivable without introducing the idea of the creation of energy. So far as human beings are concerned, this idea is as inconceivable as the idea of the creation of matter. The determination of this limit with the close accuracy necessary for a well-founded constant is to be entirely attributed to Thomson and Joule. In his $185 \mathrm{r}$ Paper Thomson thus succeeds in answering the questions which he put to himself in his 1849 Paper, and he supplies a quantitative method of connecting the amount of the thermal agency necessary with the amount of work which can be performed under varying conditions.

Engineers dealing with motive power are thus deeply in debt to Thomson and Joule for the secure position occupied by them to-day.

The brilliant work of Meyer, published so early as 1842 , is held by some to have anticipated to a large extent both the work of Thomson and of Joule. Undoubtedly Meyer formulated true ideas and carried his generalisations through a wide range. Helmholtz also very early arrived at similar conclusions to those of Joule and Thomson; but it has been thought better to discuss the work of Thomson and Joule separately, in order to illustrate the transition period through which many distinguished minds were passing about the time. Undoubtedly great credit is due to Meyer, Helmholtz, Clausius, and Hirn, and Thomson himself recognised this in the most generous way.

The ideas of Thomson and Joule now form so much of the basis of all reasoning upon motive-power engines that there is some little danger to the present generation of forgetting what they owe to these two great men. To appreciate the step made by them it is necessary to consider the position of motive power produced by heat at about the middle of the last century. At that time many attempts had been made to displace the steam engine as a heat engine by air engines in various forms-both engines heated externally and those heated internally, now known as internal-combustion engines. Papers read at the Institution of Civil Engineers in 1845 and 1853 , and the discussion of those Papers by eminent men of the day, supply an accurate measure of the knowledge possessed by the engineer of the principles of action of his heat engines. Many distinguished names occur in these Papers and Discussions, including James Stirling, Robert Stephenson, Sir George Cayley, Charles Manby, James Leslie, C. W. Siemens, Hawksley, Pole, W. G. Armstrong (afterwards Lord Armstrong), Edward Woods, E. A. Cowper, D. K. Clark, Benjamin Cheverton, Goldsworthy Gurney, George P. Bidder, Prof. Faraday, Isambard K. Brunel, Captain Fitzroy, and F. Braithwaite. At the date of the later of these discussions Brunel had already designed the Great Eastern, in 1852 , with its engines of 11,000 horse-power. Armstrong was a Fellow of the Royal Society, and had started the Elswick Works and invented the Armstrong gun. Robert Stephenson was at the height of his fame. He was then a Member of Parliament, President of the Institution of Civil Engineers, and a Fellow of the Royal Society. Siemens was a young man, but was busy on the regenerative furnace; had considered

No. 2030 , vol. 78$]$ 
regeneration as applied to steam engines, although his work on the air engine was still to come. All were distinguished mon in their day, and their opinions may be taken as representing the very best scientific knowledge of the leading engineers of the day. The first of the Papers to which I refer is called " Description of Stirling's Improved Air Engine," by James Stirling, M.Inst.C.E. It was read on June 1o, 1845 , with Sir John Rennie, the President of the Institution, in the chair. The engine described was the later form of the well-known Stirling air engine, invented by the Rev. Dr. Stirling, a S.cottish clergyman, in the year $\mathrm{I} \mathrm{I}_{5}$. The development considered was the invention of the reader of the Paper, a brother of Dr. Stirling. The main improvement consisted in the use of air at a greater density than the atmosphere, and the engine at that date had so far succeeded that two had been used at the Dundee Foundry Company's works-one giving about $2 \mathrm{I}$ horse-power and the other about 45 horsepower. Practically, therefore, some success had been attained. Mr. Stirling claimed that the $2 \mathrm{I}$-horse engine consumed $501 \mathrm{~b}$. of coal per hour, which is about $2 \frac{1}{2} 1 \mathrm{~b}$. per horse-power per hour. This was an extraordinarily good result for the time. At present, however, we are not interested in the practical result, but only in the opinions of the engineers of the day as to the fundamental principles of heat engines.

It is clear from the Paper that the theory of the regenerator was entirely misunderstood. It was imagined that with a perfect regenerator no heat would be required to perform work. This is evident from Mr. Stirling's answer to Sir George Cayley. Sir George Cayley described his engine, which was of the internal-combustion type, acting with solid fuel under constant pressure, and showed that, owing to dust and heat in the cylinder and valves, his experiments proved abortive. He stated, however, that his engine had consumed $6 \frac{1}{4} \mathrm{lb}$. of coke-equal to $9 \mathrm{lb}$. of coal-per horse-power. To this Mr. Stirling answered: "It must be remarked that Sir George Cayley, in following an entirely different object, had overlooked the great leading principle of repeatedly using the same heat," and "he was of opinion that, except on that principle, the air could not be economically used as a moving power." Another speaker, Mr. Cottam, said: "It was evident that, if it was practicable to arrive at the theoretical condition of the absorption of all the caloric by the thin laminæ during the upward passage of the air and the giving it out again during the downward passage, there would not be any loss of heat." Mr. Robert Stephenson did not appear to understand Stirling's air engine at all, because he made the following remarks: "He understood the process to consist of heating the air in a vessel, whence it ascended to the cylinder between numerous thin laminæ, by which the caloric was absorbed, to be again given out to the descending air. Now it appeared to him that, though the ascending process was natural and easy, the reverse action would require a certain expenditure of power, in the depression of the plunger." "This remark clearly showed that Stephenson, notwithstanding his eminence as an engineer, at that date had not appreciated the essential conditions of the hot-air engine.

In the year 1853 the subject of the air engine again came up before the Institution of Civil Engineers, interest being excited evidently by the building of the large engines of the hot-air ship Ericsson in America, the encines having air cylinders of no less than i 4 feet diameter. Four Papers were read in this year: "On the Use of Heated Air as a Motive Power," by Beniamin Cheverton; "On the Caloric Engine," by Charles Manby; " On the Principle of the Caloric Air Heated Engine," by James Leslie, M.Inst.C.E. : and "On the Conversion of Heat into Mechanical Effect," by Charles William Siemens, A.M.I.C.E.

Cheverton evidently considers, from his Paper referring to Stirling and Ericsson, that "Both parties also rest the efficiency of their engines on the repeated use of caloric. They contend that in recovering from the ejected hot air the caloric which gave it superior tension, and employing it in heating the injected air, 'it is made to operate over and over again.' Mr. Ericsson aspires to embody a new principle in motive mechanics-no less, to use his own words, than 'that the production of mechanical force by heat is unaccompanied by the loss of heat,' except such as arises from radiation, or other practically unavoidable waste." Cheverton rejects this idea, but, strangely enough, does not appear aware of the work either of Carnot or of Joule. He comes to the conclusion, however, that "caloric, doubtless, is in all its aspects a manifestation of force, and unquestionably, as a mechanical agent, of a dynamic force, and therefore is directly amenable to the third law of motion." He appears to think that heat is accompanied with molecular activity, but is puzzled by what he accepts to be a fact, that in the steam engine the whole of the heat of the steam as it comes from the boiler is found in the condenser. With regard to the steam, he says: "Undoubtedly, in respect to the materiality of caloric, if it be material, it is transferred intact to the condenser, yet in its passage it may have parted with force, which it cannot communicate again." He comes to the conclusion that the change may take place, not in the quantity, but in the intensity of heat. Here he resembles Carnot; but it appears to him impossible to arrive at any useful theory of the heat engine, because he states : "... for every investigation leads to the conclusion that the effect of caloric is independent at least of the chemical, if not also of the physical, constitution of bodies. But economy of fuel is a different question from the economy of caloric; it is altogether a practical matter, and can only be determined by experiment; for this, and, indeed, most other points of practice, are too intractable to come within the grasp of the most powerful calculus." In the discussion a communication was read from Sir George Cayley, in the course of which he states, with regard to the regenerator: "There can exist no doubt of the effective re-application of heat to an almost unlimited extent by this beautiful invention, due originally to $\mathrm{Mr}$. Stirling, and now carried out to a greater extent by Captain Ericsson." Sir George Cayley discussed the difficulties of Ericsson's engine, but he accepts the principle that heat may give work and yet be used over and over again practically undiminished. Armstrong did not express himself upon the theory at all, but he was doubtful as to the advantage of the air engine compared with the steam engine, although he believed that it was practicable to recover and use over again a large proportion of the heat applied, and he thought the balance of economy, so far as heat was concerned, would be found in favour of air. Siemens agreed to some extent in the advantages of a regenerator, but he showed clearly that expansion doing work was accompanied by a diminution of temperature, and stated that this heat had to be replaced by the fire. Bidder was of opinion "that no theoretical advantage was obtained in using heated air instead of vaporised water as a motive power, and it was incapable of being applied practically with as much convenience." It is most interesting to note that Dr. Faraday joined in this discussion. He said very little, and I will give his remarks complete. Dr. Faraday said: "Twenty years ago he had directed his attention to this question, and from theoretical views he had been induced to hope for the successful employment of heated air as a motive power; but even then he saw enough to discourage his sanguine expectation, and he had, with some diffidence, ventured to express his conviction of the almost unconquerable practical difficulties surrounding the case, and of the fallacy of the presumed advantages of the regenerator. He still retained his doubts as to the success of the innovation, and feared the eventual results, even of Captain Ericsson's spirited and ingenious efforts.", Brunel considered the use of the regenerator to be an entire fallacy, and did not believe that the power derived from the expansion of air by heat could be used effectively, and then be recovered and used again. Mr. Hawksley considered that the machine involved a mechanical fallacy and that the regenerator produced no mechanical effect whatever. Mr. Rendel was the President at the Meeting which dealt with Mr. Cheverton's Paper, and, in view of the great differences of opinion on the subject, he stated that "he would not have the Meeting arrive at a hasty or erroneous conclusion on the question of this engine, and he therefore suggested that Mr. Siemens should draw up a Paper on the subject, and that the Members should collect, for a future Meeting, all the information within 
their reach, in order to the calm and deliberate discussion of the question." This resulted in the further Meeting of May 17, 1853, when Papers were read by Manby, Leslie, and. Siemens. The Paper by Manby consists of the summary of a discussion by M. Galy-Cazalet, which took place in Paris in $185^{2}$. M. Galy-Cazalet comes to the conclusion that the regenerator involves a fallacy, and he concludes: "There appears to be at present so much doubt of the utility of the regenerator that it would be wise to abandon its use for a time, and by trials with a more simple form of caloric engine establish the fact either of the superiority or of the inferiority of heated air in comparison with steam as a motive power." Mr. Leslie, on the contrary, in his Paper upholds vigorously the accuracy of the principle of the regenerator or economiser. $\mathrm{He}$ comes to the conclusion that it is based on true principles and is attended in practice with real economy of heat, and consequently of fuel. In this conclusion he is doubtless correct; the regenerator is useful and does economise heat. But Leslie goes much further than this; he appears to support Stirling in the fallacy that the regenerator may be made indefinitely useful. Stirling states :-

"And thus it appears that by applying air successively to a series of bodies regularly increasing in temperature, and moving it alternately from one end of the series to the other, it may be heated and cooled ten times, with an expenditure of caloric which would barely have heated it once, if it had been applied at once, to the hottest body (i.e. beyond the series). It is evident also that if the series had been composed of twenty points, or bodies, having a difference of temperature of five degrees, the air might be heated and cooled twenty times at no greater expense of caloric. Nay, it is evident that by multiplying the members of the series indefinitely air could be heated and expanded and made to do work at no appreciable expense. But let no mathematician be alarmed with the idea of a perpetual motion, or the creation of power. There are many enemies to contend with in the air engine besides friction, which alone prevents perpetuity in some mechanical motions. We have no means, without consuming a part of our power, of applying the air so closely to the apparatus as to make it absolutely assume the temperature of the bodies to which it is applied. There is, therefore, a loss in the very act of heating and cooling.'

Leslie comes to the conclusion that Stirling is right, but that an air engine without a regenerator would be a much less effective and economical application of heat than the steam engine. Leslie gives some interesting particulars of the later air engines of James Stirling. He states that an engine of 45 horse-power was started in March, 1843 , at the Dundee Foundry; that in December, 1845 -two years and nine months after starting-one airvessel gave way, and in May, 1846 , another failed, and in January, 1847 , a third failed. This information was supplied to him by Mr. David Mudie, one of the lessees of the foundry.

We now come to Siemens' Paper " On the Conversion of Heat into Mechanical Effect," and for the first time we find the engineer guided by an intelligible principle. Siemens discussed the material theory of heat, and accepted unreservedly the dynamical theory, for which he gives a large measure of credit to Joule. This is the first of the Institution Papers in which I find the name of Joule. Siemens mentions Carnot, Clapeyron, Holtzman of Mannheim, Joule, Helmholtz, Meyer, Rankine, and Prof. Thomson. Curiously enough, although Siemens mentions Carnot and the other philosophers who dealt with the Carnot principle, including Thomson, he does not appear at this date-May $I 7,1853$-to have realised himself the effect of the law of Carnot upon the theory of the heat engine. He clearly appreciated the. first law, and gives the mechanical equivalent. of heat as determined by Joule at 770 foot-pounds, and by Thomson's formula as 772 footpounds, but in his discussion of the principles of the heat engine he is of opinion that a perfect engine is ideally possible giving 770 foot-pounds for each Fahrenheit heatunit employed. This is clear from a Table found on p. 33 of the Paper, which I reproduce:-

NO. 2030, VOL. 787

$\begin{array}{cccc}\text { Description of Engine } & \begin{array}{c}\text { Theoretical } \\ \text { Performance } \\ \text { in } \\ \text { foot-pounds }\end{array} & \begin{array}{c}\text { Actual } \\ \text { Permance } \\ \text { in }\end{array} & \begin{array}{c}\text { Actual } \\ \text { forformance } \\ \text { in pounds of } \\ \text { Coal per } \mathrm{H} \text {.P.P. } \\ \text { per Ho.1r. }\end{array}\end{array}$

A Boulton and Watt con. densing engine, low $\begin{array}{ccc}\text { pressure } \ldots & \ldots & \ldots\end{array}$ Combined steam and expansive ether engine ... The expansive air engine... Stirling's engine $\quad \ldots \quad \ldots$

Ericson's engine $\cdots \cdots$ A Perfect engine $\quad \ldots . \quad \ldots \quad 770^{\circ}$

$\begin{array}{rrrrr}51.8 & \ldots & 29 & \ldots & 8.00 \\ 158.8 & \ldots & 82 & \ldots & 2.38 \\ 150^{\circ} 0 & \ldots & 75 & \ldots & 3.09 \\ 91.0 & \ldots & 35 & \ldots & 6.63 \\ 130^{\circ} 0 & \ldots & 65 & \ldots & 3.57 \\ 196.0 & \ldots & 65 & \ldots & 3.57 \\ 770^{\circ} 0 & \ldots & 385 & \ldots & 000\end{array}$

He apprehends the mechanical equivalent of heat, but he still appears under the impression that if heat be added to a certain upper temperature and expansion take place until the original temperature is reached, then he has a perfect engine indicating the full result of Joule's mechanical equivalent. He sees, however, that the old theory of the regenerator is quite wrong. He states :-

"The cause of the failure of Mr. Stirling's engine in practice may apparently be traced chiefly to insufficiency of heating surface, occasioned apparently from misapprehension of the principle involved, it having been thought that the same heat would serve over and over again to produce power, and that the necessary expenditure of heat consisted only in the mechanical loss by imperfect action of the respirative plates, which were approached to each other to the utmost limits, consistent with an unobstructed passage of the air. By the aid of the dynamical theory of heat it has been shown that there is another and far more important expenditure of heat, which should have been provided for."

Siemens, in the discussion, rightly upheld the regenerator as useful, and saw that there were limitations to its use. Mr. Hawksley contended that the regenerator was useless. Mr. Pole considered that the regenerator was useful, but he did not definitely adopt the mechanical theory of heat. He stated :-

"It must be allowed that the general action of caloric in producing power was still involved in much obscurity. The heat was often considered in reference to its quantity only, but it was certain also that its intensity performed a very important part; and it had even been surmised that power might be obtained by the reduction of intensity alone, without any change of quantity."

Armstrong concurred with Siemens and Pole. $\mathrm{He}$ believed in the utility of the regenerator, limited as described by both. Mr. Edward Woods certainly understood Siemens to have given $77^{2}$ foot-pounds as the efficiency of an ideal heat engine, because he stated that this showed there was still great room for improvement in engines. Mr. E. A. Cowper had clear ideas; he said:-

"Steam, or gases, in expanding. and so giving out power, lost heat. Part of the sensible heat became latent in the production of power, and this heat could only be recovered by expending the power already produced in again condensing the steam back to its original bulk, when the latent heat again became sensible."

This discussion, then, puts us in the position of engineers at the date of the last Meeting referred to-May 17. 1853. Of all the distinguished engineers who spoke, Siemens alone had thoroughly apprehended the value of Joule's results and understood the full bearing of the mechanical equivalent of heat. He had not, however, understood Carnot's reasoning on the Carnot cycle, or Thomson's deductions from Carnot. He was under the impression that heat added in any way to a working fluid, raising the temperature, could be entirely converted into work by a sufficient expansion. $\mathrm{He}$ had not appreciated that, even if expansion be carried far enough to reduce the temperature to the original temperature before heat addition, yet complete conversion of the entire mechanical equivalent was impossible. When so able a man as Siemens had at this stage only reached partial enlightenment, it was evident that much hard work and clear thinking required to be done before a well-founded theory of heat motive- 
power could be obtained. The data for such a theory were accumulating; and one of the most interesting circumstances connected with these Institution of Civil Engineers Papers was a communication from M. Regnault to Colonel Sabine, Treasurer of the Royal Society, dated April, $18_{53}$, which was read at the Meeting, in which Regnault stated that

"He was about to publish immediately a series of elaborate experimental researches on various subjects connected with the effects of heat on elastic fluids, the results of which would solve many questions long in dispute, and by means of which engineers might accurately calculate the effect of a given amount of fuel, in whatever way it was applied. M. Regnault communicated in anticipation that he had arrived at the number $\mathbf{0 . 2 3 7}$ for the specific heat of air at constant pressure, and at 0.475 for that of steam under atmospheric elasticity, the specific heat of water being taken in each case as unity."

True to his word, Regnault produced his admirable investigations, and succeeded in solving many problems; but he did not settle the questions to the extent he had hoped. Even at the present time doubt arises as to the very values he gave for the specific heat of air and steam. The problem proved much more difficult than he had anticipated, and for modern engine purposes it cannot be considered as wholly solved now-fifty-five years later.

This description of the position of the hot-air engine, as shown by the opinions of eminent engineers, is most useful as proving how much practical men were in need of the work of Thomson and Joule. It is not surprising that, of all the engineers present, Siemens appeared to be alone in thoroughly grasping the new ideas. Thomson's own conversion from the material theory of heat to the dynamical theory was not complete until $185 \mathrm{I}$, and although he had then succeeded in reconciling the ideas of Joule and Carnot, it is not to be wondered at that engineers two years later had not quite succeeded in grasping the combination of the two laws. This combination, however, supplied engineers with a new and accurate standard of measurement for studying and improving upon their heat engines, and they were by no means slow in grasping the help thus offered them by the abstract scientific man. The broad laws of thermodynamics have placed the theory of the heat engine in a position of certainty, which was much needed. It would be a mistake to assume, however, that even the determination of the mechanical equivalent of heat and the second law of thermodynamics expressed in terms of an absolute thermometric scale had solved all the difficulties of the engineer desiring to determine the efficiency of his heat engines. Thomson, Joule, Rankine, and their great Continental colleagues, it is true, settled once and for all the broad laws of thermodynamics, but the Carnot cycle is a cycle which is, as has been repeatedly shown, an impossible one in practice. Accordingly, actual engines have to operate upon imperfect cycles. The theory of these imperfect cycles has been worked out mostly during the last twenty-five years, although Rankine made a beginning in dealing with the theory of the Joule air engine. For the first time he showed the existence of what may be termed a cycle of constant efficiency in the case of the Joule air engine. Assuming constant specific heat for the working fluid, he calculates the efficiency of what we now call a constant-pressure air engine between certain limits of temperature, and he gives the efficiency of the fluid where $\mathrm{U}=$ energy exerted and $\mathrm{H}_{1}=$ heat received, and $r=$ ratio of compression and expansion :-

$$
\frac{\mathrm{U}}{\mathrm{H}_{1}}=\mathrm{I}-\frac{\mathrm{I}}{r 0408} ;
$$

that is, he indicates in this formula that the thermal efficiency is independent of the maximum temperature so long as that maximum temperature exceeds the temperature of adiabatic compression. He makes no statement, however, that this engine is within a certain range independent of the maximum temperature; that is, that increasing maximum temperature does not increase efficiency. Subsequent work has shown that, on a simple assumption, such as constant specific heat, many engine cycles exist of a practicable nature having high theoretical efficiencies where the theoretical efficiency depends on one thing only-the ratio of compression. Some misunderstanding has arisen with regard to these imperfect cycles, and it has even been thought that such imperfect cycles would be contrary to the second law of thermodynamics. Lord Kelvin himself was of this opinion in $188 \mathrm{I}$. I vividly remember a conversation I had with him at the Crown Iron Works, in Glasgow, over the results I had obtained from one of my early gas engines. I had then come to the conclusion that the "Otto" cycle as ordinarily operated was a cycle of constant efficiency, and I explained this to Lord Kelvin. He had not followed such cycles, and his view then was that no such cycle could exist, because he thought it was contrary to the second law of thermodynamics. Some idea of this kind has been held by many scientific men, and has prevented the minute investigation of imperfect cycles of different kinds, because of the feeling that the whole question of efficiency was entirely settled by the nature of the temperature limits; that is, by the maximum and minimum temperatures at the disposal of the engineer. It is true that these values, as has been shown, must always determine the extreme limit of possible efficiencies between certain temperatures, and in cycles of constant efficiency the particular efficiency of the cycle is always less than the efficiency of a Carnot cycle engine working between the same limits of superior and inferior temperature. The investigation, however, of these imperfect cycles is much more difficult than the broad investigation of the general thermodynamic laws, because it requires accurate knowledge of the properties of the working fluid dealt with under conditions rendering observation extremely difficult. The modern internalcombustion motor is the successor to the air engine so fully discussed by eminent engineers of fifty-five years ago; and the forebodings of even so eminent a man as Faraday as to its ultimate success have proved unfounded. Great difficulties have been encountered and many discrepancies have had to be explained, but a minute study of the nature of the working fluid has rendered it more and more possible to calculate the efficiencies to be expected under practical conditions. At the present time we can deal with almost any cycle or any working fluid with some fair approximation to an accurate result. Much work, however, is required before all problems of the working fluid can be said to be solved with regard to any heat engine. Indeed, it may be said that under modern conditions of the use of steam even the properties of the working fluid-steam - have not yet been satisfactorily determined. The mere question of specific heat, for example, of steam and its variations of temperature and pressure is now under review, and important experiments are in progress in Britain and on the Continent to determine those properties. The properties of the working fluid of the internal-combustion motor are also the subject of earnest study by manv Continental and British investigators. Notwithstanding all the perplexities involved in the minute study of the imperfect heat-engine cycles, we are in a very different position to-dav compared with the engineer of 1853 : We know all the broad laws as to the conversion of heat into work or of work into heat; and, numerous as are the problems yet to be solved, we at least profit bv the guiding light set out for us by Kelvin, Joule, and Rankine.

\section{SECTION $\mathrm{H}$}

ANTHROPOLOGY.

Opening Address by Prof. William Ridgeway, M.A.,

F.B.A., Litt.D., Ll.D., President of the Section. The Application of Zoological Laws to Man.

THIRTy years ago in this very city I heard for the first time a Presidential Address at the British Association, and. I was singularly fortunate in entering on my novitiate. I had the privilege of hearing Prof. Huxley deliver his Presidential Address to the embryo of that Section over which I, a very unworthy successor, have this day the honour to preside. On that occasion Huxley dealt almost exclusively with the physical evolution of man, and the Neanderthal skull played an important part in his discourse. The anthropologists of that day and since have severely criticised, and rightly so, the old teleological doctrine that everything except man himself had been

NO. 2030, VOL. 78 ] 
created for man's use, and they emphatically enunciated the doctrine that man himself has been evolved under the same laws as every other animal. Yet the anthropologists themselves have not always carried out in practice their own principles to their logical conclusions. To-day I shall attempt to show that the chief errors which impede the scientific study of man, which lead to the maladministration of alien races, and which beget blunders of the gravest issue in our own social legislation, are due in the main to man's pride in shutting his eyes to the fact that he is controlled by the same laws as the rest of the animal kingdom.

I. Let us first consider some of the chief problems which at present are being debated by the physical anthropologists. Foremost in importance of these is the stratification of populations in Europe. It has generally been held as an article of faith that Europe was first peopled by a non-Aryan race. Of course it is impossible for us to say what were the physical characteristics of Palæolithic man, but when we come to Neolithic man the problem becomes less hopeless. It has been generally held that the first Neolithic men in Europe, whether they were descended or not from their Palæolithic predecessors, had long skulls, but were not Aryan; that later on a migration of shortskulled people from Asia passed along Central Europe and into France, becoming what is commonly termed the Alpine, by some the Ligurian, by others the Celtic race; that later these two primitive non-Aryan races were overrun by the Aryans, who, when these theories were first started, were universally considered to have come from the Hindu Kush, but are now generally believed, as held by Latham, to have originated in Upper Central Europe. Yet, although the view respecting the cradle of the Aryans has changed, anthropologists have not seen the important bearing that it has upon the problem of Neolithic man. The Aryans are generally held to have had a blonde complexion.

As our discussion must from its nature concern itself with questions of race, let us first examine the criteria by which anthropologists distinguish one race from another. If you ask an anthropologist how he distinguishes an Aryan from a non-Aryan race, he will tell you that he relies on three main tests : $(a)$ the colour of the skin, hair, and eyes; (b) the shape of the skull and certain other osteological characteristics; and $(c)$ the system of descent through males. Formerly language was included in the tests of race, but when it was pointed out that the Negroes of Jamaica speak English, those of Louisiana French, henceforward it was assumed that one race can embrace the language of another with the greatest ease. Yet it may turn out, after all, that language was too hastily expelled from the criteria of race. On the other hand, we may find that too implicit faith has been placed on the three criteria of cranial characteristics, pigmentation, and law of succession.

(a) As it is assumed that all Aryans were blonde and traced descent through males, so it is held that all Europeans, who are dark-complexioned, and whose forefathers traced descent through women, are non-Aryan in race, and that, although they now in almost every case speak an Aryan tongue, this is not their primitive speech, but simply that learned from their Aryan conquerors. According to this orthodox view, the dark-skinned inhabitants of Italy, Spain, and Greece are all non-Aryan, and all have borrowed the language of their masters, whilst of course the same is held respecting the melanochrous population of France and of the British Isles. Ever since Prof. Sergi comprehended under what he terms the "Eurafrican species" all the dark-complexioned peoples of Southern and Western Europe, as well as the Semitic and Hamitic peoples of Western Asia and Northern Africa, the doctrine that the dark-skinned peoples of Europe once spoke a non-Aryan tongue or tongues is supposed to have been finally established. But under his Eurafrican species Sergi includes the blonde race of Northern Europe who speak Aryan languages along with the dark races who speak non-Aryan tongues. It is argued that as all the dark-skinned peoples on the north side of the Mediterranean belong by their physical type to the same original stock as the Semites and Hamites, they must likewise have spoken non-Aryan languages. Yet it might as well be maintained that the Finns, who speak a non-Aryan tongue, and the Scandinavians, who speak an Aryan, were originally all of one stock, because both races are blonde.

This doctrine of a Mediterranean race depends upon the tacit assumption made by the physical anthropologists that identity or similarity of type means identity of race. Yet this assumption does not bear the test of scientific examination, for it assumes that only those who are sprung from a common stock can be similar in physical structure and coloration, and it leaves altogether out of sight the effects of environment in changing racial types, and that, too, in no long time. The change in the type of the American of New England from that of his English ancestor and his approximation to the hatchet face and thin, scraggy beard of the Red Indian have long been remarked, whilst the Boers of South Africa, in less than I50 years, have quite lost the old Dutch build, and become a tall, weedy race. The effects of climatic conditions are very patent amongst the native peoples of the New World. The Iroquois of the temperate parts (lat. $40^{\circ}-45^{\circ}$ ) of North America were a tall, rather light-complexioned race, but as we keep moving south and approach the equator, their kindred tribes grow somewhat darker in complexion and more feeble in physique, except where they live at a considerable altitude, for of course altitude acts in the same way as latitude. When once we pass below the equator the physique keeps steadily improving until we come to the Pampas Indians, a vigorous race who defied all the efforts of the Spaniards to subdue them; and finally we meet the Patagonians (lat. $40^{\circ}-53^{\circ}$ ), a fine, tall, light-complexioned race, who form in the south the counterpart of the Iroquois and their closely allied tribes in the north.

The same law, as is well known, can be seen at work in Europe. Starting from the Mediterranean, we meet in the lower parts a melanochrous race; but gradually, as we advance upwards, the population as a whole is growing less dark, until finally, along the shores of the Baltic we meet the tallest and most light-complexioned race in the world. Of course it has been explained that the change in pigmentation, as we advance from south to north, is due to the varying proportions in the admixture of the blonde race of the north with the melanochrous of the south. But it is difficult to believe that the movements up or down of the people from the southern side of the Alps, or of those from the shores of the Baltic, have been so nicely proportioned as to give the general steady change from north to south in coloration without the aid of some other force. The case of America, which I have just cited, is in itself enough to raise a suspicion that climatic influences are at work all the time, and that environment is in reality the chief factor in the variation of both stature and pigmentation from the Mediterranean to the Baltic. The white race of the north is of the same proximate ancestry as the dark-complexioned peoples of the northern shores of the Mediterranean. I have already argued elsewhere that, as the ice-sheet receded, mankind kept pressing further north, and gradually under changed climatic conditions the type changed from area to area, and they all still continued to speak the same Indo-European tongue, but with dialectic variations, these also being no doubt due to the physical changes in the vocal organs produced by environment.

If we turn from man to the other animals we find a complete demonstration of this doctrine. For instance, the conditions which have produced a blonde race on the Baltic have probably produced the white hare, white bears, and the tendency in the stoat and the ptarmigan to turn white in winter, whilst in the same regions of Europe and Asia the indigenous horses were of a dun colour, who not only turned white in winter, but had a great tendency to turn white altogether. It may be objected that the Lapps and Eskimo are not tall and blonde, but on the contrary short and dark; but they live within the Arctic circle in regions where the sun does not shine at all for a great part of the year, and consequently they are quite outside the conditions of environment under which the tall, blonde race of North Germany has long dwelt. Of course, in dealing with man we are always confronted with the difficulties arising from his migrations; but if

NO. 2030, VOL. 78] 
we can find a family of lower animals who cannot be said to have thus migrated, and who show the effects of environment, we shall be able to argue powerfully from analogy.

The horse family supplies the example required. If we follow it from Northern Asia to the Cape of Good Hope, we shall find that every belt has its own particular type, changes in osteology as well as in coloration taking place from region to region. First we meet the old dun horse, with its tendency to become white, the best European examples of which were probably the now extinct ponies of the Lofoden Isles. In Asia, Prejvalsky's horse is the best living instance-a dun-coloured animal with little trace of stripes. Bordering on the Prejvalsky horse or true tarpan come the Asiatic asses: first the dzeggetai of Mongolia, a fawn-coloured animal, the under-parts being Isabella-coloured; then comes the kiang of the Upper Indus valley, seldom found at a lower altitude than 10,000 feet, rufous-brown with white under-parts, whilst, as might be expected from its mountain habitat, its hind-quarters are much more developed in length and strength than in the asses of the plains. The Onager indicus, onager and hemippus are found in all the great plains of the Punjab, Afghanistan, Western India, Baluchistan, Persia, and Syria, whilst a few are said to survive in South Arabia. All these are lighter in colour than the kiang, the typical onager being a white animal with yellow blotches on the side, neck, and head. All the Asiatic asses are distinguished by the absence of any shoulder stripe, though they occasionally show traces of stripes on the lower parts of the legs. The southern Asiatic asses just described, in their greyer colour and smaller hoofs approximate to the wild asses of Africa, especially to those of Somaliland, whilst it is maintained that in their cry, as well as in their colour, the kiang and dzeggetai come closer to the horse, the next neighbours of which they are.

Passing to Africa, we firt the ass of Nubia and Abyssinia showing a shoulder stripe, and frequently with very strongly defined narrow stripes on the legs, the ears being longer than those of the onager. But in closer proximity to South-Western Asia comes the Somali ass, which differs from those of Nubia and Abyssinia by being greyer in colour, by the entire absence of shoulder stripes, and by smaller ears, in all which characteristics it comes closer to its neighbours on the Asiatic side than it does to its relations in Abyssinia and Nubia.

Next we meet the zebras. First comes the magnificent Grévy zebra of Somaliland, Shoa, and British East Africa. It is completely striped down to its hoofs, but the coloration of the specimens from Shox differs from that of those from Somaliland and from those of British East Africa. The Grévy zebra has its hoofs rounded in front like those of a horse, but its ears are more like its neighbours the asses than those of any other zebra.

In the region north of the river Tana the Burchelline group of zebras overlaps the Grévy, and though it differs essentially in form, habits, and shape of its hoofs from the Grévy, some of those in the neighbourhood of Lake Barringo show grid-iron markings on the croup like those on the Grévy zebra, whilst, like the latter, they also possess functional premolars.

All the zebras of the equatorial regions are striped to the hoofs, but when we reach the Transvaal, the Burchelline zebra, known as Chapman's, is divesting itself of stripes on its legs, whilst the ground colour is getting less white and the stripes less blark. Further south the true Burchell zebra of the Orange River has completely lost the stripes on its legs and under-surface, its general colouring being a pale yellowish-brown, the stripes being dark brown or nearly black. South of the Orange River the now extinct quagga of Cape Colony had not only begun to lose the stripes of its under-part and on the hind-quarters, but in Daniell's specimen they only survived on the neck as far as the withers, the animal having its upper surface bay and a tail like that of a horse, whilst all specimens of quagga show a rounded hoof like that of a horse.

In the quagga of $30^{\circ}$ to $32^{\circ} \mathrm{S}$. we have practically a bay horse corresponding to the bay Libyan horse of lat. $30^{\circ}-32^{\circ} \mathrm{N}$.

But the production of such variations in colour does not require great differences in latitude. On the contrary, from a study of a series of skins of zebras shot for me in British East Africa, each of which is from a known locality and from a known altitude, there can be no doubt that such variations in colour are found from district to district within a comparatively small area.

In addition to the two species of zebra already mentioned, there is the mountain zebra, formerly extremely common in the mountainous parts of Cape Colony and Natal, though now nearly extinct in that area. Its hind legs, as might naturally have been expected from its habitat, are more developed than those of the other zebras, just as these same limbs are also more developed in the kiang of the Himalayas than in any other ass.

With these facts before us, there can be no doubt that environment is a most potent factor, not only in coloration, but also in osteology. No less certain is it that environment is capable of producing changes in animal types with great rapidity. Thus, although it is an historical fact that there were no horses in Java in 1346 , and it is known that the ponies now there are descended from those brought in by the Arabs, yet within five centuries there has arisen a race of ponies (often striped) some of which are not more than two feet high. Darwin himself has given other examples of the rapid change in structure of horses when transferred from one environment to another, as, for instance, when Pampas horses are brought up into the Andes.

Another good example is that of the now familiar Basuto ponies. Up to 1846 the Basutos did not possess a single horse, those of them who went down and worked for the Boers of the Orange River usually taking their pay in cattle. At the date mentioned some of them began to take horses instead. These horses were of the ordinary mixed colonial kinds, and we may be sure that the Boers did not let the Basutos have picked specimens. The Basutos turned these horses out on their mountains, where, living under perfectly natural conditions, their posterity within less than forty years had settled down into a welldefined type of mountain pony.

Nor is it only in the horse family that we meet with examples of the force of environment. The tiger extends from the Indian Ocean, through China up to Corea, but the tiger of Corea is a very different animal from that of Bengal. Instead of the short hair of the Indian tiger, the Corean has clothed himself with a robe of dense long fur to withstand the rigours of the north. It is not unlikely that if we had a sufficient number of skins from known localities we could trace the change in the tiger from latitude to latitude, just as I have shown in the case of the Equidæ.

Now whilst there is certainly a general physical type common to all the peoples round the Mediterranean, it by no means follows that all those peoples are from the same original stock. On the contrary, the analogy from man in other parts of the world, as well as that of the Equidæ, suggest that the resemblance between the Berbers, who speak Hamitic, the Greeks who speak Aryan, and the Jews and Arabs who spoke Semitic, is simply due to the fact that those peoples, from having long dwelt under practically similar conditions in the Mediterranean basin, have gradually acquired that physical similarity which has led Sergi to the assumption that they have a proximate common ancestry, and that they accordingly form but a single race.

Nor is there any lack of instances of convergence of type under similar conditions in the case of the lower animals. We saw that the asses of South-Western Asia approximate in colour to the asses of North-East Africa, and in respect of the size of the ears and absence of shoulder-stripe, more especially to the nearest of these, the ass of Somaliland. Yet it does not follow that they are more closely related to the Somali ass than they are to their own next neighbours, the kiang. On the contrary, it is much more likely that the Somali ass is closely related to those of Abyssinia, and that the South-Western Asiatic asses are closely related to the kiang. The approximation in colour, absence of shouldcr-stripe, and size of the ears between the asses of Somaliland and those of South-Western Asia must rather be explained by a convergence of types under the somewhat similar climatic conditions of Somaliland and the nearest parts of South-Western Asia. Again, though

No. 2030, VOL. 78$]$ 
there are very strong specific differences between the Grévy and Burchelline zebras met in the neighbourhood of Lake Barringo, there is a curious approximation not only in marking but also in the teeth between these two species, which is best accounted for by supposing that it is the outcome of similar environment. It may be said that this approximation may be due to the interbreeding of the two species of zebras in the region where they overlap. This, in itself a most unlikely contingency from all that is known of the habits of wild species, certainly cannot be alleged in the case of the convergence in type between the asses of South-Western Asia and the Somali ass, since they are separated by the Red Sea and the Persian Gulf.

Again, the representative of the crocodile family in the Ganges is distinguished by the extreme elongation of the head and jaws, whilst the same elongation of the head is equally characteristic of the representative of the dolphin family found in the same waters. Again, all through the Indian Ocean wherever any family of crabs have become inhabitants of coralline sands its members have long legs. Again, it has long been noticed that in Cutch all the larger animals have a tendency to become a sandy colour, whilst in certain areas of South America insects, no matter to what family they belong, have a tendency to one common aspect.

It may of course be said that the changes in colour of the horse family, tigers, and insects are for "protective" reasons. But the case of the horse family alone is sufficient to dispose of this objection. The kiang of the Himalaya had no dangerous enemy until man was armed with a rifle. In Africa the zebras have had only two formidable foes-man and the lion. It is asserted by the most experienced hunters that the gaudy livery of the zebra makes him conspicuous from afar, whether he is on the mountain, on the plain, or in the shade of a tree. His brilliant colour therefore really exposes him to man. But it will be said that it is well adapted to conceal him at night, at which time the lion seeks his prey. Yet as the best authorities hold that the lion hunts entirely by scent, the coloration of the zebra affords him no protection against his inveterate foe.

I have shown that in horses the colours-such as bay, black, grey, and white-accompany certain well-defined inward qualities. But as black is most certainly not a primitive horse colour, it follows that coat colours may be intimately connected with certain other characteristics quite irrespective of protective colouring. Again, as the variation in the size and shape of the ears and hoofs of the asses and zebras cannot be set down to protective colouring, but must be due to other causes, there is no reason why variations in colour should not be ascribed to similar causes.

The argument based on the analogy of the horse family and the tigers, and on that of the natives of the New World, may be applied to the races of Africa. Next to the Mediterranean lie the Berbers and their Hamitic congeners, who are regarded as part of the Eurafrican species by Sergi and his'school. But the Berbers are not all of the typical Mediterranean physique. The blonde Berbers of the highlands of Rif in North-West Morocco and of the Atlas have long been well known. In the region lower down and in Western Tunis the occurrence of the xanthochrous type seems much less frequent, whilst further east it practically disappears.

It is certain that there was a fair-haired element in Libya long before Rome conquered Carthage or the Vandals had passed into the ken of history. Callimachus testifies to the existence of blonde Berbers in the third century B.c. We may hold, then, with Sergi and others that the blonde element in the Berbers is not a survival from invasions of Vandals or Goths, or from Roman colonists, but that they rather owe their fair complexions and light-coloured eyes to the circumstance that they were cradled in a cool, mountainous region, and not along the low-lying border of the Mediterranean like their darkcoloured relations whose language and customs they share.

If, then, some of those who speak Hamitic are fair. and have been fair for centuries before Christ, as Sergi himself admits, whilst others are dark, there is no reason why some of the peoples who speak Aryan might not lie dark whilst others are blonde.

The Berbers and their Hamitic congeners shade off on the south into other peoples, but this is not altogether due to intermarriage, as is commonly held, for it is mote probably to be explained as due in a large part to climatic conditions. The Bantus, who are said to have originated in the Galla country and to have spread thence, are now regarded by the chief authorities as the result of an inter mixture of Hamites and Negroes. But, on the ground. I have already stated, it is more rational to regard then as having been evolved in the area lying between the Hamitic peoples on the north and the Negroes on the south, just as we have corresponding types of the horse family in Nubia and Abyssinia and in the equatorial regions. The same hypothesis also explains the existence of those cattle-keeping tribes which lie west of the Nile stretching across Northern Nigeria, who border on the Berbers, but yet differ from them, and border also on the Negroes, but differ from them likewise. South of these tribes come the Negroes, the true children of the equator. The Bantu is able to live in elevated equatorial areas and he has burst his way down to the subtropical and temperate parts of South Africa, where he especially flourishes in the highlands, thus showing that his race was originally evolved under similar conditions. The Bantu found in the South the Hottentots, who are especially distinguished by steatopygy, a feature which has led some to identify them with the primitive steatopygous race supposed to have once lived in Southern Europe, Malta, and North Africa, and to have left evidence of their characteristic in their representations of themselves. But, granting that such a race once lived in North Africa and Southern Europe, there is really no more reason for supposing that they and the Hottentots formed one and the same race than there is for assuming that Daniell's quagga, which was practically a bay horse, was proximately akin to the bay horse of North Africa. The occurrence of steatopygy in two areas so wide apart is not due to an ethnical migration, but rather to similar climatic conditions producing similar characteristics.

As some anthropologists so commonly explain the origin of races such as the Bantus by intermarriage, it may be well to see whether intermarriage between two races, one of which is an invader, is likely to produce a permanent effect upon the general physique of a whole community. I have shown elsewhere that the many invasions of fairhaired races into the three southern peninsulas of Europe and into the Ægean islands have left no permanent trace on the population. It is a matter of common knowledge that the offspring of British and native parents in India have a constant tendency to die out. The same undoubtedly holds true for the offspring of British soldiers serving in Egypt, the Soudan, and West Africa. The native race always reasserts itself. In America the Spanish blood has died out, or is dying out, everywhere except in the temperate regions of Chile, Quito, and Argentina, where the descendants of the Spanish settlers thrive in a climate very analogous to that of Spain. In the Southern States of North America the whites cannot flourish, and only just manage to survive. On the other hand, the descendants of the Negro slaves imported into Brazil, the West Indies, and the Southern States of North America thrive and multiply with extraordinary vigour, a fact doubtless due to their race having been evolved under similar conditions in equatorial Africa.

Even from the evidence already to hand there is high probability that intermarriage can do little to form a new race unless the parents on both sides are of races evolved in similar environments.

I have already pointed out that although the fair-haired race of Upper Europe has age after age kept pouring over the Alps into Italy and the other southern peninsulas, and have constantly intermixed with the indigenous populations, it is only in the upper part of Italy that the blonde race is able to hold its own. In Italy the xanthochrous race in ancient times, as to-day, had its maximum along the Alps, and gradually dwindled towards the south until the melanochrous race stood practically alone in the lower part of the peninsula. So too in the Balkan, whilst the

No. 2030, vol. 78$]$ 
fair-haired element was at its maximum along the Alps and the Danube, southwards the melanochrous becomes more and more completely dominant, as it practically is to-day in the lower part of the peninsula.

(b) In the Alpine regions there has been from Neolithic times a brachycephalic race, also found in Central France and in the british 1sles, whither it is supposed to have come in the Bronze age. It has been a fundamental article of faith with sergi and others that this roundheaded race came from Asia, the home of brachycephalism. It is Mongolian according to most, and spoke a non-Aryan language; but Sergi regards it as Aryan, thus reverting to the old doctrine, which made the Aryans come from Central Asia, and he assumes that these invaders imposed their language both on the aborigines of Italy, such as the Ligurians, and on the blonde race of Northern Europe; but we shall soon see that this assumption has no base. Now, as these folk dwelt in the region where we find the Ligurians of historical times, others have argued that the Ligurians were a non-Aryan people from Asia. But it is impossible to find any hard-and-fast lines between the Alpine race and the peoples north and south of it in culture and sociology. For that reason when treating of the people of the Alps in my "Early Age of Greece " I did not take any account of the difference in cranial measurements. In 1906, at the British Association, I maintained that this difference of skull type did not mean any racial difference, and on the analogy of the changes in the osteology of the Equidæ I urged that the roundness of the skulls was simply due to environment, as the horses of the Pampas when brought up into the mountainous regions of Chile and Peru rapidly change their physical type. Physical anthropologists have already maintained that the round head of the Mongolian has been developed in the high altitude of the Altai. If that be so, there is no reason why a similar phenomenon should not have taken place in the Alpine region, in Albania, Anatolia, and wherever else in mountain areas brachycephaly has been found in more than sporadic examples, which of course may well be due to migrations or importation of slaves. But I am far from suggesting that altitude is the only cause of brachycephaly.

The evidence then, so far as it goes, points to the same conclusion as that to which we came as regards pigmentation, and it may eventually be proved that just as each area has its own type of coloration, so also has it its own osteological character. In support of this I may point out that recently Dr. William Wright, Hunterian lecturer, has come to the conclusion from his craniological investigations that the brachycephalic Alpine race was evolved on European soil, whilst Dr. C. S. Myers has been led by his researches on Egyptian skulls to conclude that, " in spite of the various infiltrations of foreign blood in the past, modern Egypt contains a homogeneous population which gradually shifts its average character as we proceed southwards from the shores of the Mediterranean to Nubia beyond the First Cataract."

It is not impossible that Alpine environment may have acted upon the shape of the skull of the ox as well as that of man. We know from the examination of the fauna of the Lake dwellings of Switzerland that the Celtic ox (Bos longifrons) was there the common type, and its descendants still continue to be the typical breed along the Alpine chain. This $o x$ is characterised by its strongly developed occipital region and its small horns curved forward and inward. As it differs so essentially from the urus (Bos primigenius) and from the long-horned cattle of the Mediterranean lands, it seems not unlikely that the peculiar cranial formation may have been evolved under mountainous environment.

It is now clear that differences in the shape of the skull and in the colour of the skin, hair, and eyes cannot be at all implicitly relied on as criteria of race. The defenders of the non-Aryan character of the dark races of Greece, Italy, Spain, France, and the British Isles have now to depend on two arguments only, one of which is linguistic, the other sociological. It is admitted that it is very difficult to point to any non-Aryan survivals in the vocabularies of the languages of these countries, and it is also admitted that in them all the tense system of the Aryans has been taken over in its entirety. Neither Kretschmer nor anyone else has ventured to affirm that there is any survival of non-Aryan syntactical forms in Greek, the language of all others in which the Aryan tense system is tound in its greatest delicacy and perfection. But we know that in all cases where an Aryan language has without doubt been adopted by a non-Aryan folk the tense system is invariably broken up. No better example than this is needed than ordinary "pigeon" English. So difficult is it for the defenders of the non-Aryan theory of the origin of the aborigines of Greece to maintain their position that one of the latest, Prof. Burrows, has to rely on certain supposed syntactical survivals of a non-Aryan language which Sir John Rhys believes that he has found in Welsh and Irish and in the remarkable resemblance which Prof. Morris Jones thinks that he has traced between the syntax of those languages and that of Berber and ancient Egyptian.

Yet when we examine the evidence on which Sir John Rhys relies, it turns out to be only three Welsh and Cornish oghams, written not in pure Celtic, but in dog Latin, and also two Irish oghams, which show a looseness in the use of the genitive suffix at a time when final syllables were dropping out of use in Irish. Sir John Rhys supposes that the non-Aryan inhabitants of these islands derived their Gaelic speech from a people whom he terms Celticans, who spoke Goidelic, and who were followed by the Brythons, who found the aborigines already Celticised. Prof. Morris Jones freely admits that the aborigines must have borrowed the full Aryan tense system, a fact in itself sufficient, from what I have already said, to arouse grave suspicions as to the validity of any arguments based on supposed fundamental grammatical differences. But this supposed taking over of the full Aryan tense system by the non-Aryan aborigines of these islands is rendered all the more miraculous from the circumstance that Sir John Rhys holds that his Celticans who spoke Goidelic "came over not later than the great movements which took place in the Celtic world of the Continent in the sixth and fifth centuries before our era," that the Brythons came over to Britain between the time of Pytheas and that of Julius Cæsar," and that the Brythons were not likely to come into contact on any large scale with the aborigines "before they had been to a considerable extent Celticised." It is thus assumed that it was possible for the aborigines to have been so completely Celticised as to have adopted the Aryan tense system, as well as the Aryan vocabulary, in its fulness in the interval between the sixth or fifth century and the second century B.c. Yet English has been the master speech in Britain for many centuries, and that, too, when reading and writing have been commonly practised; yet Gaelic still survives, whilst Welsh not only survives, but flourishes. It is therefore simply incredible that such a complete transformation as that postulated could have taken place in three or four centuries in an age when writing and literature can be hardly said to have existed in these islands.

Let us now see under what conditions does one race or people borrow the language of another. Slaves of course take over the language of their masters, but we have to consider (I) the adoption by a conquering people of the language of the conquered; (2) the adoption by a conquered people of that of their conquerors; and (3) the adoption by a people, themselves unconquered, of the language of their neighbours. Under what conditions do the conquerors adopt the language of the conquered? Ireland affords us at least two certain examples. Cromwell planted large bodies of his English soldiers in Tipperary, but they had no English women, and therefore took as wives the daughters of the land, who spoke the Irish language. From this union resulted a splendid offspring, who spoke chiefly the language of their Irish mothers, and not their fathers' English. So it came to pass that in a single generation the progeny of Cromwell's Puritans were in language as Irish as the purest-blooded aboriginal of Munster. Yet this adoption of the Irish language by the great majority of the children of these settlers took place in spite of the effect which the reading of books in English must have exerted to counteract the tendency to adopt the Irish language. Let us go back five hundred years in Irish history, and we find exactly the same process going on. The Normans who followed Strongbow into Ireland, like their captain, frequently married native women. It

NO. 203O, VOL. 78 ] 
is a matter of common knowledge that the Anglo-Norman settlers in a short time became Hiberniores ipsis Hibernis.

These and other examples too numerous to cite here prove that the children of bodies of conquerors who marry the women of the land will have an inevitable tendency to follow their mothers' speech. We may also lay down as a solid factor in the tendency of the conqueror to merge into the conquered the isolation of the conquerors from their original homes and from the great mass of those who speak the same language.

Next we come to the case where the conquerors bring with them some women of their own race. This of course helps to keep their own language alive, as a certain number of the children speak it as their mothers' tongue. But even in these circumstances the invaders are liable to drop their own language and practically adopt that of the natives. Thus the Northmen who settled on the coast of France gradually abandoned their national tongue for French, though modifying dialectically their adopted language. When under the name of Normans they conquered and settled in England, they again adopted the language of the conquered, though modifying the English tongue by many words and phrases brought with them from Normandy, and we have just seen how some of their descendants who settled in Ireland for the third time changed their speech for that of the conquered.

Hitherto all our examples show the adoption by the conquerors of the language of the conquered, even when they bring a certain number of their women with them.

We now come to undoubted cases where the language of the conqueror has been able to get a firm foothold. From the time of the plantation of Ulster, the advance of the English tongue, and consequent decadence of the Irish, has steadily proceeded, for the settlers, unlike Cromwell's Ironsides, brought with them women of their own race and speech. Consequently their children grew up speaking English as their mothers' tongue. Yet even with such a basis the advance of English amongst the Irish has been exceedingly slow. In the glens of Antrim the Irish language still lingers on, whilst in Donegal, Connaught, Kerry, Cork, and Waterford, English has not succeeded in ousting completely the native language, though the former is the language of the national schools, of the newspapers, and of trade.

The story of the establishment of English itself in Britain is just the same as in Ulster. We know from Bede that the Angles. who settled in Britain left Holstein in large bodies, bringing with them their wives and families, and leaving their old homes without inhabitant. Having thus settled in solid masses in the east of Britain, they retained fully their own tongue, impressed it upon their menials, and gradually, as they extended their conquests westward over the island, English became the language of the land. Yet in Wales the ancient speech still flourishes.

We may therefore conclude that the adoption by the conquered of the language of the conqueror, even when it does take place, which is but rarely, is a very slow and tedious process, although every advantage is on the side of the invading tongue, and that when the native speech gets a fair field, as in Wales, the language of the conqueror can make little or no advance.

Only the third possibility now is left-that one people can adopt without conquest the language of another. But no example of such can anywhere be found, although Europe presents numerous instances to the contrary. There can be no stronger case than that of the Swiss Republic, in which peoples with more than four kinds of language combine for national defence and other advantages. Here, if anywhere, we ought to find a gradual adoption by certain cantons of the language of their neighbours. But, far from this being so, the German, French, Roumansch, and Italian cantons rigidly preserve their respective motherspeeches. In the Austro-Hungarian Empire there is no tendency observable on the part of either Magyars or Slavs to adopt German; nay, the very opposite is the case. Again, the Finns have not adopted either Swedish or Russian, though partitioned between their more powerful neighbours.

To sum up, it seems that no nation readily adopts the language of another, even though it be in close ties of friendship; whilst there is still less tendency when national hostility intervenes. Secondly, the adoption of the language of the conqueror by the conquered, except in the most favourable circumstances, is not common, and only takes place by a very gradual process, as is seen in the case of Ireland. Thirdly, there is a strong tendency for the conqueror to adopt the language of the conquered, as was done by the Normans in England, in Ireland, in Sicily, and in Italy; by the Cromwellian settlers in Tipperary, by the Bulgari in Bulgaria, by the Franks in Gaul, by the Lombards in Italy, and by the Visigoths in Spain. There is thus an inevitable tendency for the children to speak their mothers' tongue, and indeed the phrase " mother-tongue" is based on the fact, observed through long ages, that the child learns its first words from its mother, and thus takes after her in speech. This law, which still holds good in modern days and in civilised communities, must have been far stronger in earlier times in countries where the tie of marriage hardly existed and the child belonged to its mother's and not to its father's tribe, as is still the case in many parts of the world.

In view of these facts we cannot accept Sir John Rhys's hypothesis that when a few bodies of invade:s, whom he terms Celticans, passed into Ireland the indigenous supposed non-Aryan race within two centuries completely abandoned its own language, taking over in its entirety the Aryan tense system as well as the Aryan vocabulary of its conquerors.

Now let us turn to Greece, Italy, and Spain. It is admitted that neither Arcadia nor Attica was ever conquered by Acheans or Dorians, yet in both these areas the Greek language existed through all historical time, and in Attica especially the Aryan tense system is found in its highest perfection. The dialect of Arcadia cannot have been taken over from Acheans or Dorians, because it is the same as that of the Cypriotes from Arcadia who settled in Cyprus at least Iroo B.C. It is also very close to the dialect of Pelasgiotis in Thessaly, the home of the aboriginal Pelasgian population, whilst it comes closest of all Greek dialects to that of the ancient Epic. There can therefore be no doubt that Arcadian is no mere bastard lingo, half non-Aryan, half Aryan, but is the genuine speech of the oldest and most unmixed population of Greece, who were undoubtedly a melanochrous race, and who also most certainly had occupied Greece from the Stone age.

The Ligurians, who formed from the Stone age the bottom stratum in all Upper and Central Italy, are now admitted to have spoken an Aryan language, and I have recently given some reasons for believing that the Latin language is simply the native tongue of the aboriginal Ligurian population of Latium with some admixtures derived from the Italic tribes of Siculi and Sabines. I have also shown that the ancient Iberians, the next neighbours of the Ligurians, used the same forms of placenames as the latter, and that some of the words plainly exhibit Aryan terminations. Thus we may conclude that with the exception of the Basques, who are probably a nonAryan spurt from North Africa, the melanochrous populations of Spain, Italy, the Balkan Peninsula, France, Britain, Ireland, and Holland have from the first spoken none but an Aryan language.

(c) Only one argument is now left to the defenders of the non-Aryan theory. When the study of sociology first sprang up in the last century, it at once became a fundamental doctrine that the Aryans had always been strictly patriarchal, and that polyandry and descent through women was unknown amongst them. Though this view has received many rude shocks in later days, Prof. Zimmer argues from it that the indigenous people of Britain and Ireland were non-Aryan.

It is well known from the ancient writers that the Picts were polyandrous, and that succession was consequently through females. Again, it is certain, both from the ancient Irish literature and also from statements of external writers, that the Irish were polyandrous, and that they also almost certainly traced descent through women. Accordingly Prof. Zimmer infers that the indigenous race was non-Aryan. But McLennan has long since pointed out that descent through women was the ancient law at Athens, and I have just shown that the Athenians and Arcadians, the autochthonous, dark-complexioned people of Greece NO. 2030 , VOI. 78 ] 
never spoke any save an Aryan tongue. Moreover, I have shown elsewhere that the Ligurians, who are now generally admitted to have spoken always an Aryan language, had descent through women, whilst I have also pointed out that there is good evidence that the ancient Latins, who have generally been taken as typical Aryans, had the same system. Again, it is admitted that the ancient Illyrians and dark-complexioned Thracians spoke an Aryan language, which, inasmuch as it differed materially in certain ways from that spoken by their Celtic overlords, must have been aboriginal, whilst I have further given grounds for believing that the ancient Iberians (though not the Basques) were also an Aryan-speaking folk. But there is good evidence that the Illyrians, melanochrous Thracians and Iberians all traced descent through women. In view of these facts it is useless to urge that because the Picts of Scotland and the ancient Irish had that system of succession through females these peoples must have been non-Aryan.

We have now reviewed the three main criteria of race at present used by anthropologists : (a) pigmentation of the skin, hair, and eyes; $(b)$ the shape of the skull and other osteological characteristics; and finally $(c)$ their system of tracing descent. We have seen that osteological differences may be but foundations of sand because it is certain that such variations take place within very short periods, not only in the case of the lower animals, as in the horse family, but in man himself. Pigmentation is no true criterion, for we have found a steady tendency to change in colour in the case of the lower animals from latitude to latitude, whilst in the case of man the steady shading off in colour from dark to blonde may be traced from the equator to the Baltic. Unless then we postulate that man is entirely free from the natural laws which condition the osteology and pigmentation of other animals, we must admit that neither bone nor colour differences can be regarded as crucial criteria. Further, we saw that the test of descent through males or females broke down absolutely in the case of peoples who can be proved historically never to have spoken any but a non-Aryan language. Finally, we are forced to the conclusion that language, now that we realise what are the laws which govern its borrowing by one race from another, is really the surest of all the known tests of race when dealt with broadly and over wide areas, and not merely in the way of guesswork etymologies.

II. Hitherto I have dealt only with the need of a rigid application of zoological laws in studying the evolution of the various races of man. In the time that is still left I propose to touch briefly on the vast importance of such natural laws when dealing with the native races of our great dependencies and colonies, and in our own social legislation. I venture to think that the gravest mistakes which at present are being made in our administration and legislation are due to the total disregard of the natural laws, which not only modify and differentiate one race from another, but also are constantly producing variations within our own community. As physical characteristics are in the main the result of environment, social institutions and religious ideas are no less the product of that environment. Several of our most distinguished Indian and Colonial administrators have pointed out that most of the mistakes made by British officials are due to their ignorance of the habits and customs of the natives. It has been in the past an axiom of British politicians that in the English Constitution and in English law there is a panacea for every political and social difficulty in any race under the sun. Only let us give, it is urged, this or that State a representative parliamentary system and trial by jury and all will go well. The fundamental error in this doctrine is the assumption that a political and legal system evolved during many centuries amongst a people of NorthWestern Europe, largely Teutonic, and that too living not on the mainland but on an island, can be applied cut and dried to a people evolved during countless generations in tropical or subtropical regions, with social institutions and religious ideas widely different from those of even South Europeans, and still more so from those of Northern Europe. We might just as well ask the Ethiopian to change his skin as to change radically his social and religious ideas. It has been shown by experience that Christianity can make but little headway amongst many peoples in Africa or Asia, where, on the other hand, NO. 2030, VOL. 78 ]
Mohammedanism has made and is steadily making progress, acting distinctly for good, as in Africa, by putting down human sacrifice and replacing fetish worship by a lofty monotheism. This is probably due to the fact that Mohammedanism is a religion evolved amongst a Semitic people who live in latitudes bordering on the aboriginal races of Africa and Asia, and that it is far more akin in its social ideas to those of the Negro or Malay than are those of Christianity, more especially of that form of Christianity evolved during the last twelve centuries by the Teutonic peoples of Upper Europe, who are of all races furthest in physical characteristics, in religious ideals and social institutions, from the dark races of Africa and Asia. This great gulf is due not merely to shallow prejudice against other people's notions, it is as deep-seated as is the physical antipathy felt by the Teuton for the Negro, which is itself due to the very different climatic conditions under which both races have been evolved. The Teuton does not freely blend with the black, and even when he does intermarry he treats his own half-bred progeny with contempt, or at most with toleration. On the other hand, some South Europeans, for example the Portuguese, are said to have little objection to intermarrying with dark races and allowing the mixed progeny an equal social status, whilst the Arab through the ages has freely taken to wife the African, and has never hesitated to treat the hybrid offspring as equals. There is thus a wide breach between the physique and the social and religious ideas of the African and our own; but, as political and legal institutions are indissolubly bound up with social and religious, it follows inevitably that the political and legal institutions of a race cradled in Northern Europe are exceedingly ill adapted for the children of the equator. Accordingly in any wise administration of these regions it must be a primary object to study the native institutions, to modify and elevate them whenever it may be possible, but never to seek to eradicate and supplant them. Any attempt to do so will be but vain, for these institutions are as much part of the land as are its climate, its soil, its fauna, and its flora. "Naturam expellas furca, tamen usque recurret." Let us hope for a successful issue for the effort now being made by the Royal Anthropological Institute to establish an Imperial Bureau of Anthropology the function of which will be, not only to carry out systematically the scientific study of man, but also to aid the administrator and the legislator, the merchant and the missionary.

III. I now pass to my last and most important topicnatural laws in relation to our own social legislation. We have seen that environment is a powerful factor in the differentiation of the various races of man, alike in physique, institutions, and religion. It is probable that the food-supply at hand in each region may be an important element in these variations, whilst the nature of the food and drink preferred there may itself be due in no small degree to climatic conditions. Each zone has its own peculiar products, and beyond doubt the natives of each region differ in their tastes for food and drink. The aboriginal of the tropics is distinctly a vegetarian, whilst the Eskimo within the Arctic circle is practically wholly carnivorous. In each case the taste is almost certainly due to the necessities of their environment, for the man in the Arctic regions could not survive without an abundance of animal fat. It is probable that the more northward man advanced the more carnivorous he became in order to support the rigours of the northern climate. The same holds equally true in the case of drink. Temperance reformers would enforce by legislation complete abstinence from all alcoholic liquors, and they point to the sobriety of the Spaniards, Italians, and other South Europeans. and urge, if these nations are so temperate, why should Britons and Irish continue to drink beer and spirits in such large quantities? This appeal depends unfortunately on the false assumption that the natives of these islands enioy the same climate as the people of the sunny south. All across Northern Europe and Asia there is a universal love of strong drink, which is not the mere outcome of vicious desires, but of climatic law. In Shakespeare's time "your Englishman was most potent in potting," and this was no new outbreak of depravity, for the earliest reference in history to the natives of these islands tells us 
the same tale. When Pytheas of Marseilles travelled in these regions, about 350 B.C., he found the people making "wine from barley," and, though he does not explicitly say so, we need not doubt that it was meant for home consumption. In view of these facts we must regard this tendency as essentially climatic. This view derives additional support from the well-authenticated fact that one of the chief characteristics of the descendants of British settlers in Australia is their strong teetotalism. This cannot be set down to their having a higher moral standard than their ancestors, but rather, as in the case of Spaniards and Italians, to the circumstance that they live in a. country. much warmer and drier than the British Isles. We must therefore, no matter how reluctantly, come to the conclusion that no attempt to eradicate this tendency to alcohol in these latitudes can be successful, for the most that can be done by the philanthropist and the legislator is to modify and control it, but especially by moral means.

I. have spoken of the principles at work in the differentiation of one race from another. It may be that the same principles or others closely allied may be at work within each community, for each community is but the whole world writ small. Within the United Kingdom itself there are not only different physical types, but very different ideas respecting marriage and divorce embodied in the laws regulating those fundamental institutions in England, Scotland, and Ireland. If such fundamental differences exist in that most important of social institutions, we may well expect that the natural laws which differentiate one race from another may be at work within every community in the United Kingdom.

Yet though the world has been ringing with the doctrine of natural selection and the survival of the fittest for nearly half a century, no statesman ever dreams of taking these great principles into consideration when devising any scheme of education or social reform. On the contrary, it is a fundamental assumption in all our educational and social reforms that all men are born with equal capacities; that there is no difference in this respect between the average child of the labourer, sprung from many generations of labourers, and one born of many generations of middle or upper-class progenitors; and it is held that all that is necessary to make the children of the working classes equal, if not superior, to the children of the bourgeois is the same food, the same clothing, and the same educational advantages. On that azcount we have devised the so-called educationai ladder. Yet if we ask any social reformer why are there middle classes, the answer will probably be that they are better off. But why are they ketter off? We are told that their fathers and mothers were better off, and that they thus got a better chance than the poor labourer. But why were the parents of these middle-class folks better off? Oh! they came of families that had been long well-to-do. But why were these families long well-to-do? At last we are brought to the conclusion of the northern farmer, that "Work mun 'a gone to the gittin' whiniver munny was got," ard to his brutal correlative respecting the labourers that "Them or thir feythers, tha sees, mun 'a beän a laäzy lot.',

Work no doubt has been a main factor in the evolution of the middle and upper classes, especially in later times, though undoubtedly other qualities, such as superior physique and superior courage, have been very important elements in the earlier stages. But at all times it is not improbable that the special quality which led to their rise was a superior self-restraint, that enabled them to resist the vices which are too often attendant on prosperity. This superior morale acts in turn upon the offspring by setting up a better standard of life in the home, which of itself gives children brought up in such an environment an advantage at the outset of life denied to the children of inferior parents. It needs no elaborate induction to prove that the middle classes are not the outcome of chance, but of a long process of natural selection and the survival of the fittest in the struggle for life, the two main factors in this evolution being, in the language of Aristotle, heredity and training. Each community is but a microcosm of the whole human race, which, as I have endeavoured to show, is bound by the same laws as the rest of the animal kingdom. One race becomes a master because of its superior physique, courage, brain power, and morale; another sinks in the struggle or lags behind owing to its inferiority in the very qualities' which have given the mastery to its rival. What is true of master races in relation to inferior races is equally true of the individuals in each community. The middle and upper classes are in the main sprung from ancestors with better physique, courage, and morale, and who have generation after generation been brought up in a better moral atmosphere than the children of the masses. Their ranks are also continually being reinforced by the best of the working classes. But this is not due to any educational ladder provided in modern times, for the process has always been at work, though of course its action has been distinctly aided by modern legislation. Mediæval history supplies many examples of those who, though sprung from the humblest parents, rose to high place in Church and State. This was not due to any legislative enactments, but rather to a principle well known in the whole field of Nature. Everyone knows that the superior varieties of flowers and vegetables are commonly the "sports," as they are termed, from inferior species. The skilful gardener watches carefully for good "sports," for they may become very valuable additions to his répertoire of useful plants. So, too, the legislator must watch carefully for good human "sports," not for those with criminal propensities. In the mediæval world the Church provided a ladder by which the son of the peasant could rise to be the counsellor of kings and princes. In modern times the State provides an educational ladder by which the child of the humblest parents may rise, if it has the capacity, to the highest positions in the community. It is right-nay, essentialthat such a ladder should be provided, but this ladder is not for the mass of children. The vast majority can never climb beyond its lowest rung owing to their heredity, and in a less degree to their home environment. The ladder is for the good "sports," who by its aid are thus continually reinforcing with fresh blood the ranks of the middle and upper classes.

It may be said that I underrate the number of the good "sports." Of course it is very difficult to get any exact statistics on so complex a subject; but according to information which I have obtained from one of our great industrial centres, where the educational ladder enables any child who passes the fourth standard in the primary schools before it is eleven to rise into the secondary schools, it is probable that no more than 5 or 6 per cent. of the children of the working classes have at the age of sixteen the same amount of brain power as the average children of the middle classes at the same age. But even all this 5 or 6 per cent. of "sports" cannot be credited to parents of the working class alone, for it may be that a certain proportion of them must be ascribed to middle- or upperclass parents. Of course these rude statistics must be corrected by others collected on a large scale all over the country before we can form a final judgment; but I believe that the evidence already to hand makes it improbable that more than a very limited percentage of the children of the working classes have the same ability as the average child of the middie classes.

In ancient days the chief end of the legislator was to produce a stalwart brood of citizens capable of bearing arms in defence of their country and advancing her material prosperity. Still more ought this to be the aim of our legislators to-day, for under modern conditions great masses of population are huddled together in a manner hardly known to ancient cities. To accomplish this great end, the legislator must not merely look to improved housing of the poor and the development of the physique of city populations. He must, so far as possible, conform to the principles of the stockbreeder, whose object is to rear the finest horses, cattle, or sheep. Amongst wild animals Nature selects the fittest for continuing the race, and the wise breeder simply aids Nature by selecting still more carefully the best animals. The legislator, on his part, ought similarly to foster the increase of the best element in the State, and on the other hand discourage the multiplication of the worst. Yet in our community statesmen of both parties have adopted the very opposite policy. The children of the working classes are educated at the cost of the State, the offspring of the wastrels are 
given free meals, and already there are demands that they shall be clothed at the expense of the ratepayers, and that the parents shall even be paid for providing them with lodging. It is not impossible that before long these demands will be conceded by either party in the State. The heavy additional expense incurred in this policy falls upon the middle-class ratepayers and taxpayers, who have to feed, educate, and clothe their own children at their own expense. It may be said that they can get free education for their children by sending them to the State schools; but this is to level down instead of to level up; for if they do so, they will be lowering the general morale of their own class, the most priceless asset of the nation. The heavy burden of taxation entailed by this policy, falling as it does with special weight on the middle classes, renders it more difficult each year for the young men and the young women in that class to marry before thirty, for they naturally shrink from the expense of bringing up large or even moderate-sized families. We need not then wonder at the falling-off in the rate of increase of the middle classes. Our legislators are bad stockmasters, for they are selecting to continue the race the most unfit physically and morally, whilst they discourage more and more the increase of what we have proved to be the outcome of a long process of natural selection. The present policy therefore tends to reduce that which in all ages has been the mainstay of every State, the middle class. The yeomen of England, the free burghers of Germany and of Italy, formed the best element in the Middle Ages. So was it also with the great republics of the ancient world. Aristotle, in more than one passage, has pointed out that the middle class, that which stands between the "excessively wealthy" and the "very poor," between the "millionaire" and the "wastrel," are the mainstay of every State, and he shows that, where the middle class has been crushed out by the millionaire or the mob, ruin has inevitably overtaken the State. Indeed, it is clear that the chief defect in the Greek democracies was the smallness and weakness of the middle class, whilst it is notorious that Rome prospered only so long as the middleclass citizens flourished. Her downfall came when they were extinguished by the great capitalists, who made common cause with the masses against them. The latter had no patriotism, were incapable of bearing arms, and had no aspirations beyond free meals and popular entertainments at the expense of the State.

It is of great scientific interest to discover how the short-skulled peoples of Asia and Europe became differentiated from their long-skulled congeners: it is of great practical importance to apply to the administration of our great dependencies and colonies the lessons taught bv anthropology; but it is infinitely more important to maintain a vigorous stock of citizens for the kingdom and the empire. Questions of the origin of races are. after all. only academic; but the other two, more especially the last. are intimately bound up with the life of the nation. If the present policy of our legislators is adhered to, the moral and the physical standard of the British citizen will steadily deteriorate, for the population will gradually come to consist of the posterity of those who are themselves sorung from many generations of the most unfit. Should this unfortunately come to pass, it will be the result of human pride refusing to apply to the human race the laws which inexorably regulate all Nature.

\section{UNIVERSITY AND EDUCATIONAL INTELLIGENCE.}

St. Andrews.--Dr. Hugh Marshall has been appointed successor to Prof. James Walker, F.R.S., in the chair of chemistry in University College, Dundee, and Dr. Percy $\mathrm{J}$. Herring has been appointed to the Chandos chair of physiology in the United College, St. Andrews, in the room of the late Prof. Pettigrew, F.R.S.

Mr. T. J. REes has been appointed superintendent of education for the borough of Swansea.
THE directorship of the research hospital of the Rockefeller Institute of New York City has been accepted by Prof. Rufus I. Cole, of the Johns Hopkins University,

Mr. J. A. Gil.RUTH, chief veterinarian and Government bacteriologist of New Zealand, has been appointed director of the National Veterinary College and Research Institute now being established by the Government of Victoria, Australia.

A COURSE of public lectures on hygiene and public health has been arranged (in cooperation with the State Department of Health) for delivery at Cornell University. The introductory lecture will be given on October 8 by President Schurman.

ThE Times reports that Prof. Borgman has resigned the rectorship of St. Petersburg University as a protest against the policy of the Minister of Education; it also says that the Council of Ministers has empowered the Minister of Public Instruction to forbid women to attend university lectures in future, but to permit those to complete their studies at universities who have already received permission, and whose transfer to higher educational institutions for women is impossible.

The Royal Agricultural College, Cirencester, after an existence of sixty-three years, has been re-organised, that its sphere of activity and usefulness may be greatly widened, and that it may no longer be handicapped by non-eligibility to receive grants from public monies. Taking advantage of the enlarged powers now conferred upon it, the college proposes to advance the cause of agriculture in general, and the agricultural interests of the west of England in particular, by actively engaging in the following kinds of work:-(I) scientific research in agricultural subjects; (2) cooperation with the University of Bristol (by which it will, no doubt, be fully recognised) in the establishment of degree courses and degrees in agriculture and forestry; (3) continuance of the important work of training landowners, estate agents, and colonists; (4) training county scholars in agriculture; (5) continuing and extending the system of short courses for sons of tenant farmers; (6) establishing classes in subjects of rural education for the benefit of teachers; (7) cooperation with county councils in their instructional and experimental work; (8) acting as a bureau of information for the benefit of west of England agriculturists.

THE new session of the Birkbeck College, London, will be opened on September 28 with an address by Dr. Albert Griffiths. The new calendar, which is now available, shows that the college provides courses of day and evening instruction for degrees in arts, science, laws, and economics in the University of London, in addition to other important educational work. Twenty-eight members of the large staff are recognised teachers of the University of London. The work of the college has developed so greatly in recent years that there is pressing need for increased space. In some departments the stage has been reached where students have to be refused, and the usefulness of the college is curtailed by its limited accommodation. There is, in fact, urgent need for more spacious college buildings. We commend this calendar to intending students who live within access of the college as being likely to provide information of the kind they seek. The calendar of the Bradford Technical College for 1908-9, issued by the education committee of the city, has also been received. It not only provides full information of the comprehensive day and evening courses in technology provided at the Technical College, but also of an efficient department for external examination work, such as that in connection with the Board of Education and the Pharmaceutical Society. The volume concludes with particulars of the evening continuation schools and the branch technical and commercial schools provided throughout the city.

From time to time during the past six months handsome bequests to assist the development of higher education in the United States have been announced in Science. In addition to many gifts of ro,oool. or less, the following benefactions have been made. By the will of the late Mrs. Frederick Sheldon, $60,000 l$. has come to Harvard

NO. 2030, VOL. 78] 